\title{
ELECTRICAL PORCELAIN
}

I. TESTING With A High-Frequency OScIllator. II. The Problematical PoInts of Manufacture. III. ExPERIENCES AND EXPERIMENTAL INVESTIGATIONS

\author{
BY E. E. F. CREIGHTON
}

\section{Abstract OF Paper}

Part I treats of the reasons for using the high frequency oscillator for testing porcelain insulators. The oscillator is a combination of a 60-cycle transformer, a condenser, a spark gap, and an oscillation or coreless transformer. The 60-cycle potential charges the condenser and the condenser discharges through the gap and the coreless transformer. This sets up high frequency wave trains of the same nature as the wave trains that take place on the transmission line. This high frequency potential strain is the only kind that damages the insulators. The 60-cycle potential is always far below the puncture potential and arc-over potential of the insulators.

In Part II it is shown that the principal factors in the manufacture of porcelain which affect the final product are:

1. The choice of ingredients, - ball clay, china clay, feldspar, and flint.

2 . Is the problem involved in getting a homogeneous mixture of these pulverized materials.

3. Is the problem of drying out the moisture without causing unequal contractions which crack the green porcelain.

4. Is the early dehydration in the furnace in which as much as 14 per cent of moisture is given out.

5. Proper time and temperature for vitrification.

The mechanical processes through which porcelain is carried are of the greatest importance in getting good electrical porcelain. It can be stated that defective porcelains are in general due to the accidents of manufacture, the dielectric strength of all the porcelains being passably good except for flaws.

Part III includes data on tests carried out mostly with the high-frequency outfit. An electrical method is shown of producing failure along invisible cleavage surfaces in the porcelain body. This examination should be useful to the porcelain manufacturer to indicate how nearly the porcelain is approaching to a weakness which will cause the rejection of the porcelain piece. Another method, using potential gradient to investigate the homogeneity of the porcelain, may be found of use in determining the efficiency of the pug mill which is used to mix the ingredients when the porcelain is in the early plastic stage.

\section{OBJect OF The Paper}

IN PREPARING this paper there has been in view a number of objects. The many electrical and ceramic problems encountered are complex and widely ramified. There

Manuscript of this paper was received January $18,1915$. 
are a number of these problems which have only been mentioned. There are ceramic problems on which definite information has not yet been found. There are methods of examination of porcelain which are still in the stages of development. The experiments given are definite so far as they go but more experience is necessary to crystallize the methods into permanent forms. There is one main object which it is hoped to accomplish: namely, to call attention to the use of the high-frequency oscillator as a rational method of testing insulators.

Some of the subjects treated are listed below:

(a) A brief analysis of the general problem of continuity of service on transmission lines in which porcelain insulators assume a primary and important position.

(b) An analysis of the electrical strains which are actually imposed on insulators in practice.

(c) A description of the high frequency oscillator which has been designed to reproduce the electrical strains imposed on the insulators.

(d) A brief review of ceramic problems as involved in the manufacture of porcelain for electrical purposes.

(e) Experiences and experiments in the practical use of the oscillator and the general methods of study of porcelain.

(f) Puncturing under oil: Thickness, range of puncture voltage, form of test piece.

(g) Equivalent gap tests.

(h) Voltage of first appearance of corona on insulators.

(i) Percentage of failure as a criterion of rejection.

(j) Comparison of puncture voltage of several porcelains:

(k) Technique of examination of cracks, laminations, punctures, etc.

(1) Hot and cold tests.

(m) Tests with continuous high frequency.

(n) Study of the effect of corrugating a smooth surface and the laws of creepage spark as affected by thickness of porcelain.

(o) Methods of using super-spark potential from the oscillator.

(p) Methods of examination of quality of porcelain using voltage gradient.

(q) Determination of the proper time of test and something on the question, "Does the voltage test damage the porcelain?"

Much valuable work on electrical porcelain, comprised in a number of papers, has been presented to the American Institute of Electrical Engineers during the past few years. The 
recent steps taken by the committee on standardization of tests of insulators have had great value in crystallizing the known data and information into a definite useful form. It is here proposed to add further to the collected data and present a new method of testing insulators which the author believes should supplant the old standard method in which potential at a frequency of 60 cycles per second is employed.

It seems unnecessary to dwell at any great length on the engineering necessity of finding'a satisfactory solution of the problem of maintaining the integrity of the insulation of electrical transmission lines. It is desirable to attack this problem from every available scientific and practical standpoint. The problems relating to the integrity of the insulator are only a part of the broad problem of continuity of service on transmission circuits. A brief review of the salient factors of the broad problems is given in the following analysis, in which the position of the problem of the insulator itself is made evident.

\section{PART I}

\section{Analysis of the Broader Problem of Continuity of SERVICE}

In the first consideration we can hope only to pursue the line of investigation relating to detection of weak and damaged porcelain insulators, and either reject them if they have not yet been installed or remove them from the line if they are already in use.

In the second consideration we may hope with confidence to overcome the causes which deteriorate the insulators after they have been put into use,- - such damage as comes from unequal expansion of metal parts, cements,and porcelains. This investigation should also cover these faults which are present in the manufacture, in one form or another, such as open pores, closed pores, cracks, from unequal contractions, local strains, laminations, air pockets, localized mineral impurities, and accidental impurities in the form of threads and hair.

In the third consideration is the form of the insulator. The ideal design should be such that the porcelain shall never puncture.

In the fourth consideration is the way and means of preventing lightning from producing a potential sufficient to arc over an insulator. This involves the subject of overhead and under- 
hung grounded conductors; also the necessary factor of safety of the line insulator.

In the fifth consideration, assuming that in spite of all precautions an accidental arc is established around in insulator, what means may be employed to suppress such an accidental arc without causing or allowing an interruption of service? Herein comes the use of arcing ground suppressors and short-circuit suppressors.

In the sixth consideration is the condition of malicious or accidental interference with the power wires in which a heavy conducting strip is thrown across two conductors or two line wires are pushed together. The only possibility of continuing the service then lies in the use of a duplicate undamaged circuit and automatic relays to cause the nearest circuit breakers on both sides of the short-circuit to open and thus remove the faulty circuit.

In the seventh and last consideration is the rare occurrence of cyclones, floods, and sleet storms which destroy considerable length of the circuit. The only insurance against interruption of the user's service is then a local steam auxiliary or storage battery.

In this paper we are concerned with the first three considerations and a part of the fourth consideration, all of which deal directly with the porcelain insulator.

\section{How Should Insulators be Tested?}

We have in the past tested insulators with high potential at the available frequency of 60 cycles. In suggesting testing with high frequency it becomes necessary to differentiate between the different kinds of high frequency that can be produced by different types of apparatus. There is the continuous high frequency as given by an Alexanderson generator and there is the high frequency wave trains produced by a discharge of a condenser through a transformer having no iron core. In each case there is the question of what value of high frequency to use and what potential. These factors will be considered more in detail later but we can find immediate answer to the question of the proper tests to make by statements of the conditions to which the insulator is subjected. Insulators in practise may become faulty due to unequal expansion of metal, cement, and porcelain but even then they seldom get an opportunity to fail at 60 cycles because of the 
fact that every circuit has super-imposed on the 60 cycle potential occasional higher frequencies coming from switching and variations in load which reach the gradually developing faults in the insulator before the deterioration is sufficient to be affected by the 60-cycle wave. This whole question of what conditions of potential and frequency to impose in test on an insulator can be answered in the general statement; test the insulator under the same conditions which cause its failure in actual operation. These conditions will now be reviewed.

\section{Classification of Faults in Insulators}

There are two entirely distinct conditions of failure between which we must differentiate. First, complete failure of the porcelain by cracks, leaving only air and moisture as insulation between the metal terminals of the insulators. There is no need to discuss refinements of tests in this case. The desired tests consist simply in furnishing sufficient voltage to break down the air gap in the crack of the porcelain. If there is moisture in the air-gap an ordinary resistance test with a megger will show the presence of the crack. In the absence of moisture a higher voltage must be used. This calls for some portable testing outfit which can be carried along the transmission line and the oscillator is generally the best to use. Second, flaws consisting of small cracks, laminations, air pockets, porosity, etc. in insulators which withstand the normal 60 -cycle potential applied to them and even the higher value of 60 -cycle test potential, but will fail under the imposition of high frequency wave trains such as occur in lightning strokes, switching, etc.

\section{NOTES ON TESTING OF INSULATORS WITH THE OSCILLATOR}

\section{Problem of Testing the Thousands of Insulators Already Installed}

One of the most important points regarding the use of the oscillator lies in the fact that it can be made so light and inexpensive and easy to handle that it can be used by the transmission engineers and their assistants to test out insulators after they have arrived at their destination, and also to test out the thousands of insulators which have been installed during the past dozen years, and thereby to pick out the faulty ones. 


\section{The Conditions to which Insulators are Subjected} IN USE

In order to determine the nature of the desired electrical tests the following analysis is made. Insulators are damaged electrically, first, by lightning; second, by surges from switching; and third, by surges from accidental arcing grounds, and the like. The duration, voltage, and frequency of these surges will now be analyzed.

\section{Duration Characteristics of the Three Kinds of Surges}

Lightning has the characteristic of momentary duration but a stroke may be repeated a number of times in such rapid succession that the successive strokes appear to the eye to be one stroke. There are many records taken by moving photographic films which show conclusively that lightning does come in multiple strokes.

Switching surges are also of comparatively short duration, taking place only at the moment of closing or opening of the oil switch or the blowing of a fuse.

Surges set up by accidental grounds are frequently of considerable duration, lasting many seconds or even many minutes. Single-phase short circuits sometimes cause high voltage in other parallel circuits.

8. Rise of Voltage of the Three Kinds of Surges, and THE Frequencies Involved

In each case the rise of potential also must be considered as a factor of menace to the integrity of the porcelain insulators. In the case of lightning there is no limit to the potential except that which will cause a discharge from line to ground. In the case of switching, the voltage on the line nearly always reaches double value; and with changes of ratio of capacity and inductance in the transmission circuit or with partial resonance, the surges may rise to considerably more than double line potential. In the case of arcing grounds the voltage will usually rise to double value and there are many chances of a resonant condition existing which will carry it much above double value.

\section{The Oscillator Testing Set}

The testing set, as developed, is shown in Fig. 1. It consists of the following elements as shown in the diagram, Fig. 2.

a. A 60-cycle step-up transformer. 
b. A condenser placed across the terminals of the high voltage coils of the transformer.

c. An adjustable gap.

d. An oscillation transformer, oil immersed, without iron core, consisting of a few turns on the primary and many turns on the secondary. The regulation of this transformer is made as good as can be obtained and, unlike the wireless outfits, there is no dependence placed on obtaining resonance for the

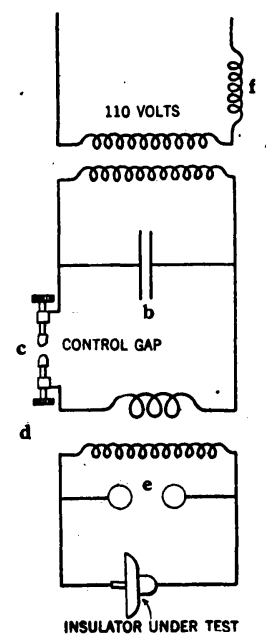

Fig. 2

Diagram of connections of the oscillator testing set for porcelain insulators.

b, condenser

c, control gap

d, oscillation transfore, sphere gap

f, series inductance ordinary tests.

e. A sphere gap made up of spheres of diameter equal to maximum air gap.

f. A suitable reactor to protect the step-up transformer against the damaging effect of short-circuit when a spark takes place on the small gap.

The ratio chosen for the 60-cycle transformer is 110 volts to 13,000 volts, as both are standard and 13,000 volts is high enough to give good effects in the. oscillator, in the set large enough to test ordinary single-unit insulators. This outfit is capable of producing a voltage represented by a setting of 125,000 volts on the sphere gap and is capable of operating at this value all day long continuously. This is the testing set recommended for general use. For testing single lower voltage insulators a smaller set can be built to meet the special needs.

The main frequency of the natural oscillation of such an outfit without the secondary of the coreless transformer in place is about 200,000 cycles per second. The range of high frequency recommended for testing is 150,000 to 400,000 cycles per second.

The maximum rate of discharge should not be less than 1000 $\mathrm{kv}-\mathrm{a}$. This maximum rate of discharge is not dependent on the kilowatt rating of the 60 -cycle transformer but depends mostly on the electrostatic condenser.

The foregoing data cover the characteristics of a testing set which is capable of testing most of the insulators in use. It is easily manufactured and satisfactory in operation. A convenient form is shown in the accompanying illustration, Fig. 1. 


\section{Control of Voltage of the Oscillator}

The voltage is controiled by gradually opening the control gap shown in Fig. 2. One electrode of this control gap is connected to a long insulating rod which permits of handling while the arc across the gap is playing. In this way the voltage is gradually increased to the desired value while it is being applied to the insulator.

The control of the voltage by the use of the control gap alone gives a very simple condition and its use is recommended in spite of an increase in the number of wave trains per second at less than quarter its maximum voltage. If this increase in the number of wave trains were a serious matter it could be taken care of in either one of two ways. First, by decreasing the total time of applications of voltage to the insulator, so as to give the same total number of wave trains, when the control gap is small and sparking over more than one per half-cycle. A test of one minute with 120 alternations per second gives a total of 7200 wave trains per minute. The other method of getting a definite number of wave trains applied to the insulator could be accomplished by reducing the voltage at the terminals of the 60-cycle transformer, thus making the peak voltage correspond with the spark voltage setting of the control gap. In this way a single wave train per half-cycle will be produced.

As a matter of experience it is found that except in special cases the variation in the number of wave trains is not a serious matter in the practical testing of insulators. There are several factors involved. First, the time of test of an insulator set at one minute or ten seconds is a quite arbitrary value and the period might well be chosen as two minutes if so desired. Two minutes would correspond to twice the number of wave trains per second. It is desirable to maintain the standard of one minute for test for reasons of economy. Second, the greater number of wave trains are produced at the lower values of voltage and the lower values of voltage correspond to small insulators on which there is a large factor of safety. As the matter stands then, there are a greater number of wave trains applied to the lower voltage insulators but they are capable of withstanding it and the extra number of wave trains applied for one minute is not sufficient to cause deterioration of good porcelain.

In Figs. 3, 4, and 5 are given three oscillograms taken in the 60-cycle circuit of the oscillator which show typical conditions for three different values of voltage generated in the secondary. 
PLATE XLIII.

A. I. E. E.

VOL. XXXIV, NO. 5

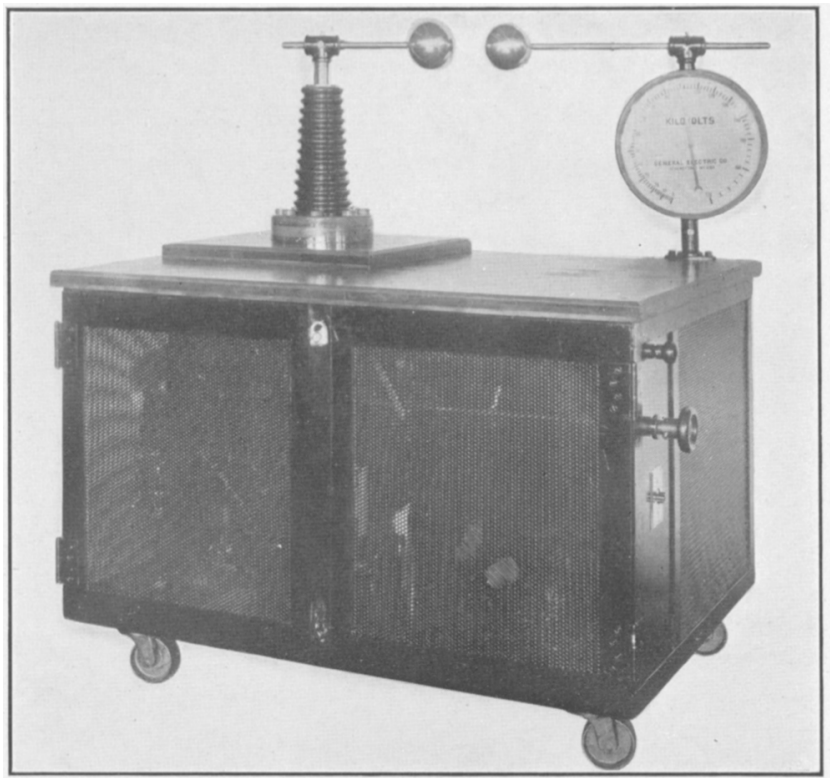

[CREIGHTON]

FIG. 1

12i-kv. oscillator with sphere gap voltmeter. Single terminal of the coreless transformer shown at the left to which one sphere is attached. The other terminal of the coreless transformer is grounded. The other sphere which carries the voltmeter is grounded so that it can be handled while the spark is playing.

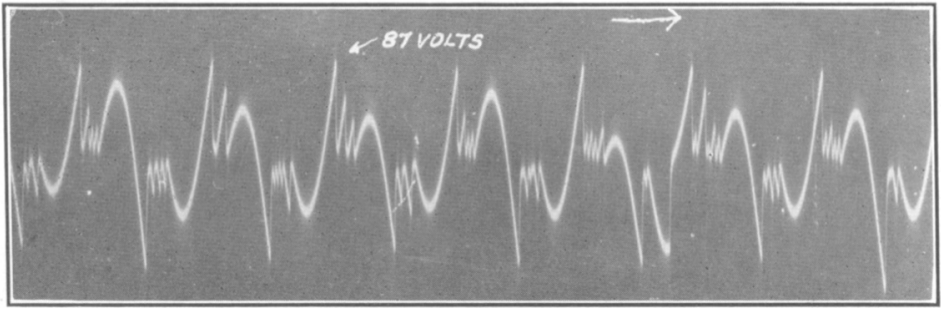

Fig. 3

[CREIGHTON]

Oscillogram of voltage in the 60-cycle circuit of the oscillator when the control gap is set for 6000 volts effective. There is only one main discharge at the control gap per halfcycle. When a spark at the control gap takes place it is indicated on the oscillogram by a sudden drop in voltage. 

PLATE XLIV.

A. I. E. E.

VOL. XXXIV, NO. 5

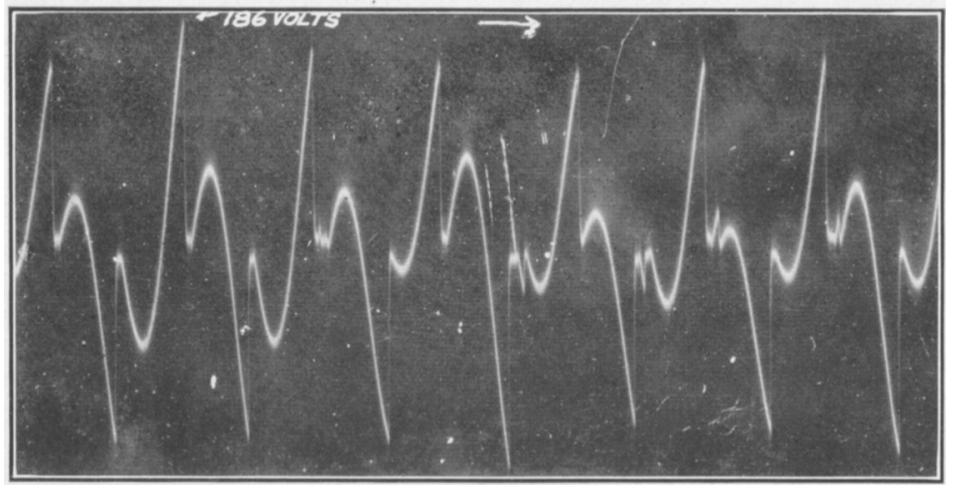

FIG. 4

[CREIGHTON]

Oscillogram of the voltage on the low side of the 60 -cycle transformer when the control gap is set for 12,000 volts. There is only one main discharge at the control gap per halfcycle of the 60-cycle circuit.

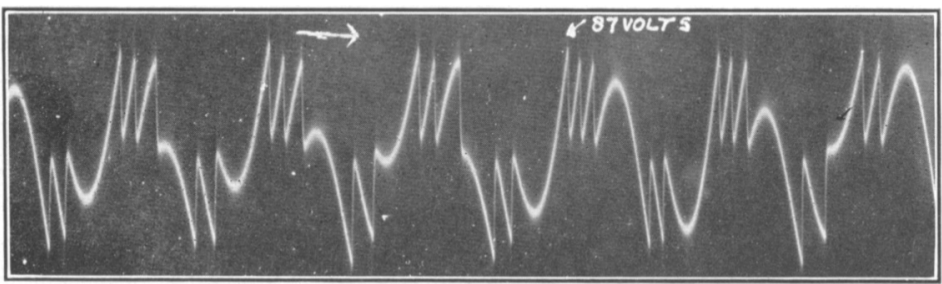

FIG. 5

[CREIGHTON]

Oscillogram of the voltage on the 110-volt side of the 60-cycle transformer. A blast of air was playing on the arc which removed the ionized gases and thereby introduced about three wave trains per half-cycle, all of which are about equal. 

Comparing oscillograms of Fig. 3 and Fig. 4 , it is seen that the voltage at the control gap may be reduced more than 50 per cent by decreasing the length of the control gap without increasing the number of wave trains per second which are effective in producing the high voltage on the secondary of the coreless transformer. In a 60-cycle circuit there are 120 alternations per second and the gap should spark over at each peak value of the 60-cycle potential. When the gap sparks over it is indicated on the oscillogram by a sudden drop. In Fig. 4 there are extra oscillations after the first peak value which re-light the spark but the voltage is so low, as compared to the peak value, that it is negligible.

In Fig. 5 an air blast is added which carried the ionized gases of the spark away and causes the voltage to rise to practically full value two or three times per half-cycle. The spark at the control gap is then extinguished and the voltage curve gradually drops into the regular 60 -cycle wave, the distortion being due to the electromagnetic energy derived from the series reactance in the 60 -cycle circuit.

\section{Measurement of Voltage}

The only available, practical method of measuring the voltage of high frequency wave trains is by sphere gap. Although the voltage may not be accurately expressed in volts, due to the unknown conditions of ionization and deionization at high frequency, and also due somewhat to the inevitable dielectrical spark lag, still there is no reason for not accepting the voltage measurement taken by the sphere gap. Since this statement may be open to question a further analysis of the object we have in view and how it differs from other voltage measurements is given in an endeavor to clarify the situation. Under the ordinary conditions of power distribution for lighting it is quite essential to have a definite voltage which can be measured and relied upon in order not to damage the lamps to which the voltage is applied or to have the voltage so low as to get an insufficient amount of light. The object in view in measuring the high frequency wave trains is not in any way similar. Therefore we do not need to have the same standard. The object in the measurement of the voltage, or more accurately stated, the equivalent sphere gap, of an insulator is the desire to know what potentials must exist at the terminals of the insulator to cause it to arc over or puncture. Although it would be of 
interest to express this tendency to spark over the insulator in terms of accurately expressed voltage, either peak value or effective value, it is not at all essential. The essential feature is to have a standard of reference with which to compare different types of insulators, different forms and conditions of electrodes, and such other features of design as produce the most reliable insulator. The sphere gap furnishes reliable means of measuring the limiting condition which will cause a spark to form over the insulator, and it is convenient to express the gap length in terms of the voltage. which will cause the gap to arc over at the usual frequency of 60 cycles.

In choosing the sphere gap the diameter of the sphere is made about equal to the maximum gap length to be used.

There is another value of voltage that it is desirable to measure for the information it gives relative to lightning arresters; that is the minimum gap setting of the spheres which will take all the discharge away from the insulator. This minimum gap setting, is considerably below the maximum gap setting which causes practically all the discharges to take place across the insulator. The intermediate values of sphere gap settings between the maximum and minimum are in general of no particular interest.

Instead of giving the equivalent sphere gap in centimeters or inches the values are translated immediately by means of the scale on the oscillator into equivalent kilovolts at 60 cycles. In some cases we have used a straight scale subdivided into kilovolts underneath the supporting rod of the grounded sphere. In another case we have attached a wire to the shank of the grounded sphere and passed this wire around a cam which carried a pointer around a circular dial as shown in Fig. 1. The large dial adds little to the expense but it has the advantage of being read more easily and is economical of time in testing.

For special conditions of study a dial has also been used on the control gap which measures the gap length. The ratio between the voltage on the control gap and the voltage produced on the sphere gaps will vary according to the load that is placed in parallel with the sphere gaps. However, for any fixed condition of load the control gap can be calibrated and used as a measure of the applied potential with a fair degree of accuracy. The control gap gives the maximum voltage generated and the sphere gap gives the maximum voltage that exists across the insulator, which is naturally less than the maxi- 
mum super-spark voltage applied. The voltage measured by the sphere gap is somewhat above the spark voltage of the insulator when the voltage is gradually increased in the usual way. The dial then on the control gap has its special uses although it is not an essential part of the testing outfit for the usual tests that have been made on insulators in the past.

\section{Kilovolt-A mpere Capacity of the Oscillator}

The kilovolt-ampere capacity of the testing apparatus is important especially where a number of insulators are tested in muitiple. The capacitance of the electrostatic condenser used with the coreless transformer, together with the inductance and regulation of the coreless transformer, determines the value of power which can be delivered by the testing outfit. The power of the oscillator is used up in producing corona over the surface of the insulator and its connecting wire. In the oscillator testing set designed for general use, there is sufficient energy io produce spark-over on five disk insulators in parallal when the electrostatic condenser has a capacitance sufficienc to store up 500 microcoulombs. By doubling the capacitance it is possible to test ten suspension type insulators in parallel. The rating of this oscillator is $125 \mathrm{kv}$. which it can carry continuously. For short periods of testing it has been used up to $175 \mathrm{kv}$. on a single insulator. It is capable of producing for an instant approximately $5000 \mathrm{kv}-\mathrm{a}$. A somewhat smaller outfit could be used for testing single insulators of the suspension type but the smaller oscillator would have less application and would require a considerable knowledge of its characteristics and adaptability to prevent its being used under conditions which would give inadequate potential stress on the insulator.

We have in the laboratory an old Tesla coil outfit which is smaller, but the kilovolt-ampere capacity of this outfit was insufficient to spark over an insulator designed for $33-\mathrm{kv}$. circuit. The corona, formed at the head of the insulator and extending out about an inch over the surface, absorbed all the available energy from this outfit far below arc-over voltage.

13. What can be Done with the Oscillator to ReproDuce Operating Conditions of Insulators

The ideal criterion for testing is to weed out all insulators which will fail subsequently in use. Tests should be made to meet these operating conditions. The method of test using the oscil- 
lator adapts itself with a fair degree of perfection to the reproduction of all of these conditions and it is only a matter of choice on the part of the engineer to get with its use the mildest or nearly the severest conditions of electric surges. These different degrees of severity of test can be obtained with greater ease and simplicity than with the 60 -cycle testing apparatus. There is needed no special motor generator set, no fussing about sinewave alternators, no question of limited kilowatt capacity due to the use of more or less resistance, no large transformer and separate means of excitation of the generator, etc. Two turns on the screw of the control gap give the full range of voltage, the maximum of which may be far above the arc-over voltage of the insulator and yet no short-circuit is produced on the oscillation transformer, such as takes place in the 60-cycle transformer when a spark occurs. The other factor involved in the tests is the duration of application which can, of course, be fully controlled by a hand switch.

\section{Tests with the Oscillator with Six Gradations of Severity and Duration}

A number of arbitrarily chosen tests graded in severity and time of application, which corresponds to surge condition in practise, are given below for illustrations.

The first gradation, che mildest test with the oscillation transformer, consists in opening the control gap gradually until a slight corona appears on the insulator but keeping the applied high-frequency potential considerably below the value which will cause a spark around the skirts of the insulator. The corona is plentiful, audible, and visible in daylight, and therefore there is no difficulty in arriving at the desired degree. If this potential is applied for a very brief time it corresponds to a light induced discharge of lightning on the line, surges from switching, and the momentary arcing ground through enough resistance to prevent high potentials. This test is too mild to have any value except when the insulator is cracked or punctured.

The second gradation of testing is the application of this potential (somewhat less than the spark potential of the insulator) during a long period of time-say from one minute to five minutes. This test corresponds to a mild condition of sustained arcing ground. Insulators that will not stand this test would surcly fail in service. The rest is also too mild to consider for practical use. 
The third gradation is obtained by opening the control gap of the oscillator so that the potential rises to a value sufficient to occasionally spark around the insulator-say once every second or so. Again this discharge may be applied for a fraction of a second corresponding to dangerous lightning discharges, dangerous surges from switching and from momentary arcing grounds.

The fourth gradation consists in applying this discharge for a longer time, ranging from one second to five minutes, which corresponds to high frequency surges generated by unusual conditions of vicious arcing grounds for a period corresponding to the duration of test. Such arcing grounds may or may not cause a short-circuit which ends the application of high voltage. Applied for one second, the test corresponds to 120 lightning strokes in quick succession of a voltage equal to the arc-over voltage of the insulator or some lesser unknown number of strokes scattered over several years. The test is very mild as a substitute for lightning strokes, as they come, of various values of potential above the value which is necessary to cause a spark around the skirts of the insulator. A duration of one minute makes a fair test and is recommended as a tentative standard.

The fifth gradation consists in opening up the control gap of the oscillation transformer so that momentarily the oscillation transformer gives its maximum voltage which should be a super-spark potential for the insulator. This voltage stress is applied to the porcelain during the brief time of dielectric spark lag that is required to form the spark around the skirts of the insulator or, otherwise, during the time necessary to puncture the porcelain. This test, applied momentarily, corresponds to a very heavy lightning discharge. It corresponds also to a rare case of switching and also to the accidental conditions where there is a cross between a high-voltage circuit and one of lower voltage. The application of a number of these single strokes is nothing more than the insulator may get in operation in due time. The surge potential corresponding to this test may not appear many times per year on a transmission system. Good continuous service suggests the test. Scarcity of good line insulators may not always permit the adoption of this as a commercial test.

The sixth gradation consists in applying this super-spark potential to the insulator for a longer period of time, of the order of 1 to 20 seconds. This latter test may very justifiably 
be considered from a conservative standpoint as more severe than is necessary, more severe than actually occurs as a rule in practise. It may, therefore, in the present state of development of insulators, be considered only as a comparative test to give the endurance of different types of insulators and may, consequently, be placed in the category known as a " design test."

\section{Tentative Recommended Tests}

There are special tests of unusual severity which it may be desirable to make as comparative between different types of insulators but with these special tests we are not concerned at the present moment. After testing many insulators the following test has been adopted for the purposes of this investigation. Raise the potential rapidly about two kv. every five seconds until an occasional spark is produced around the skirts of the insulator, a spark about every second or so; hold this potential for one minute; then raise the potential by about 20 per cent causing a flood of sparks around the insulator and hold for ten seconds.

\section{Operators' Viewpoint and Experience}

Mr. F. Osgood ai the recent meeting of the Institute emphasized very strongly that the oscillator had shown bad designs of insulators on their system, resulting in the complete elimination of all the insulators of a certain type, and furthermore, he found weakness in all the older pin types of porcelain insulators. The manufacturers of insulators were asked to produce an insulator which would stand the high-frequency test and I understand they have been able to do it. This is a step toward perfecting the insulation of a transmission line.

\section{When is the Oscillator Test Dangerous to Porcelain?}

In answer to the criticism that the method of test is dangerous, it should be noted that the surges on the line are also dangerous to the porcelain, especially if it is faulty.

The object of the test is to make it dangerous to faulty porcelain. The object should be, and before long will be, to damage and destroy every insulator which in practise would be damaged by the surges in the circuits. It will finally be good economy to do this. If the test is made to correspond to the conditions on the circuit against which the porcelain is designed to resist, then the statement of danger has only a desirable significance. 


\section{Recommendations}

Let us examine the subject in its several different aspects: 1st, old designs; 2nd, cracked, porous, or punctured porcelain of insulators already installed; 3rd, new insulators not yet installed.

First. We have not yet arrived at a condition of perfection of design of all pin insulators. Therefore, it is too early to recommend a wholesale slaughter of weak designs. Reasonable engineering judgment must be exercised in each system to weed out the insulators which are weak enough to fail under the frequently occurring surges of switching and accidental arcs; but the next better grade should not be damaged by too severe tests and should be left in place on the lines to run chances in escaping a heavy strain due to lightning, until the evolution of design and manufacture brings forth a more perfect insulator. The test of these old insulators in place should therefore be milder than it will eventually be desirable to make it. It is not difficult to get a conception of the possibility of damaging an insulator under test. A time test, as described later, made on a number of insulators will determine the possibilities of damage from the test.

If old insulators are mounted on wooden cross-arms and the pins are not grounded a much weaker insulator can be used successfully than where the pin is grounded. Still the cracked and punctured porcelains must be removed from the circuit, because a failure of the insulator causes the destruction of the supporting wood and is consequently a great menace which threatens long continued interruption of service while a pole and arm are being replaced.

Second. In the case of porous or cracked or otherwise badly weakened porcelain the test must be severe enough to show the fault.

Third. In the purchase of new insulators the requirements of test should be severe enough to show faulty design and the presence of flaws which will subsequently be developed by the surges under service conditions. Rigorous tests should be used on new insulators before installation to determine definitely that neither the design nor the quality of porcelain is poor.

\section{Is the High-Frequency Test Dangerous To Good Porcelain?}

The next question relates to the danger of the test to good porcelain. Every test which carries the electric strain up to the 
maximum limit of the porcelain is very liable to cause danger even to good porcelain. If, as it should be, the thickness of porcelain is made such that the spark potential around the skirt is very much less than the puncture potential and the design is so made that the potential gradient at any point has a reasonable value, less than the damaging value, then the recommended high frequency tests can be made without damaging good porcelain. If many insulators fail it may be an indication that they are too near the danger limit of electric stress. In further reply to this criticism, it should be recalled that the results of tests on 60 cycles have shown that the 60 -cycle potential at spark-over value may also damage porcelain.

In a paper presented to the A. I. E. E. June 1911 by Mr. Austin, he showed that the 60 -cycle potential applied to a rack of insulators would puncture quite a number of them during the first period of a few minutes and would continue to puncture insulators during every minute that the test was continued although ai a lesser number per minute as time went on. From this it is evident that at the end of a minute test there will necessarily be some porcelain insulators which are just ready to puncture and may be in a condition described as damaged. Familiarity with the rule of one minute duration of test may cause the critic to overlook this condition. The subject will be somewhat clarified by the observations on the nature of flaws given later.

Since 1911 there has been very evident progress made in the manufacture of electrical porcelain. From our observations on the use of high frequency potentials for testing insulators it would appear that defective insulators would be picked out earlier by the high frequency tests and our test results show that batches of suspension insulators delivered to the laboratory have withstood high frequency tests by the hour without losing a single insulator among them. Some tests were run continuously nine hours per day for six days with the voltage. at barely arcover value, and the insulators are still in good condition. This experience tends to show that only the faulty insulators will be picked out by the tests.

This question of damage to good porcelain in particular cases can be determined sometimes by special tests on insulators. If an insulator is tested continuously for an hour without puncturing, it is reasonably evident that a one-minute test will not damage the same porcelain and a test limited to a few seconds 
gives still further assurance. The question then of the duration of test and the damage that results thereby can be determined on special lots of insulators by the number that are damaged in a given time, which should be made long as compared to the standardized duration of test. Our own results show that an insulator of good design and good porcelain will withstand highfrequency discharge many hours. In thus comparing two different designs of insulators or two different makes of insulators, it is evident that one that withstands the discharge for the longest time will be the better insulator to use. If many insulators under test are shown to be damaged by a reasonable test it is evident that the design is faulty or the, porcelain defective. If the test is made less severe than reasonable, then poor insulators will be installed on the line. With poor insulators installed, it becomes a matter of chance before they are caught by a surge. On the ideal line there should not be used a single insulator that will puncture.

20. Porcelain is not Heated by Normal Test with the OSCILlator

A criticism of the method has been that the high frequency entails dielectric losses which it is feared will damage the porcelain There is no doubt that the high-frequency test produced more heat in the porcelain, by some sort of hysteretic effect, than comes from the application of 60 -cycles. There is also no doubt that the high frequency will reach and damage a bad spot much more quickly and much more surely than the 60 -cycle tests. In regard to this heating, however, there should be no confusion between the application of high frequency wave trains at 300,000 cycles from an oscillator and high frequency from a generator. In the case of the oscillator a wave train of high frequency is applied about 120 times per second. Between adjacent trains there is a relatively long period of rest, about 100 times the duration of a train, during which no potential is applied to the insulator. On the other hand, when the potential is supplied by a high frequency generator, the high frequency is absolutely continuous and the heating of the porcelain is correspondingly magnified. With continuous high-frequency voltage it is possible to overheat the insulator and damage it by heat alone. Even under continuous frequency nearly all the heat comes from corona in the air and very little from dielectric hysteresis in the porcelain. 
In conclusion, long-continued tests have shown that there is no danger of hysteretic heating of good porcelain insulators by the recommended tests using the wave trains of an oscillator.

\section{Heating of the Surface of the Insulator by Corona AND SPARKS}

As to the damage from heating the surface of the porcelain. it can be stated in general that the corona may take place over periods of several minutes without heating up the porcelain more than a few degrees. It is hardly perceptible to the touch. The sparks have more heating effect but nothing serious - a rise of a few degrees. There is one undesirable condition, however, which will be perfectly evident to the tester: When, due to using very heavy discharges, the spark concentrates in one fixed streak around the porcelain skirts, local heating can take place on the surface of the porcelain. This concentrated heat will usually crack the porcelain in a minute or so. This fixed spark is an improper application and can be avoided by changing the conditions of test. It should be understood that the proper testing of the insulator by high frequency consists in making the discharge take a new path around the insulator at each successive discharge, so that the appearance to the eye is that of many radial streaks of discharge fairly uniformly distributed over the whole surface of the insulator.

\section{Tests Recommended}

In the foregoing, flexible methods of tests have been laid out and criticisms of the test answered. Appended hereto it is hoped to add brief definite specifications for a fair set of tests. There is a very great advantage to be gained in the extensions of electrical transmissions by an improvement in the insulator. It is desirable that every important transmission company should have an oscillator testing set to be carried along the circuits to eliminate the insulators which are intrinsically poor in design and manufacture, and in addition, those which have been damaged either by expansion of the metal parts against the hard cement or by some crysiallization effect in the cement which makes ic expand. Factory testing does not meet the demand that not a single faulty insuiator should be installed or operated on a transmission circuit, because the insulator may be damaged in transit or by some effect which develops in the course of time. This calls for iesting on the ground. 
22. Characteristics of the 125-Kv: High-Frequency

OSCILlator

Much of the detail work of making a practical design of oscillator has been done by Mr. P. E. Hosegood. There are certain complex phases of the problems involved which are out of the scope of the present presentation. However, the important characteristics of the oscillator from a useful standpoint have been summarized by Mr. Hosegood and are herewith presented with the additions of only an occasional comment by ihe writer intended to connect the information with the rest of the paper.

One of the chief objects to be achieved in the design of a highfrequency oscillator for testing insulators is good regulation so as to be abie to test a number of insulators at once without undue drop of voltage. When insulators are connected to the oscillator the voltage falls off due to regulation. The current in the highvoltage coil supplies two conditions, viz: the loss of energy in brush discharge and the capacitance of the insulators. These conditions call for as close a coupling between the iwo coils of the oscillator as can be obtained. Owing to the variation of the capacitance of the high-tension circuit of the oscillator, with varying loads, it is impracticable, in general work to use loose coupling between primary and secondary, and depend on adjusting the inductance and capacitance for resonance. With close coupling, the voltage generated at the high-tension terminal of the oscillator will depend chiefly on the ratio of turns between primary and secondary windings of the coreless transformer.

The voltage applied to the condenser depends upon the setting of the control gap. The preferred form of control gap consists of two wheels rotated by a motor. The spark takes place between the peripheries of the two wheels. This arrangement reduced the wear caused by the spark and also maintains the spark potential at a constant value for any given length of spark gap.

Figs. 3 and 4 show oscillograms of the potential across the 110-volt primary of the 60-cycle transformer. In Fig. 1 the controi gap is set for 6000 volts effective, and in Fig. 2 for 12,000 volts. The latter is the maximum rating of the condenser. It will be noticed in both cases there is only one high-voltage spark for every half-cycle. When the spark takes place, it shortcircuits the high-voltage side of the 60-cycle transformer, and a sudden decrease in voltage across the primary occurs. The 
primary source of power is not short-circuited but the voltage is momentarily shifted from the 60-cycle transformer to the series reactance shown in Fig. 2. It is only at very low settings on the control gap that the number of wave trains per half-cycle of the 60 -cycle circuit increases materially. At low voltage it makes comparativcly little difference in the effects obtained if the number of wave trains per second does increase.

In Fig. 5 an air blast is applied to the control gap which was

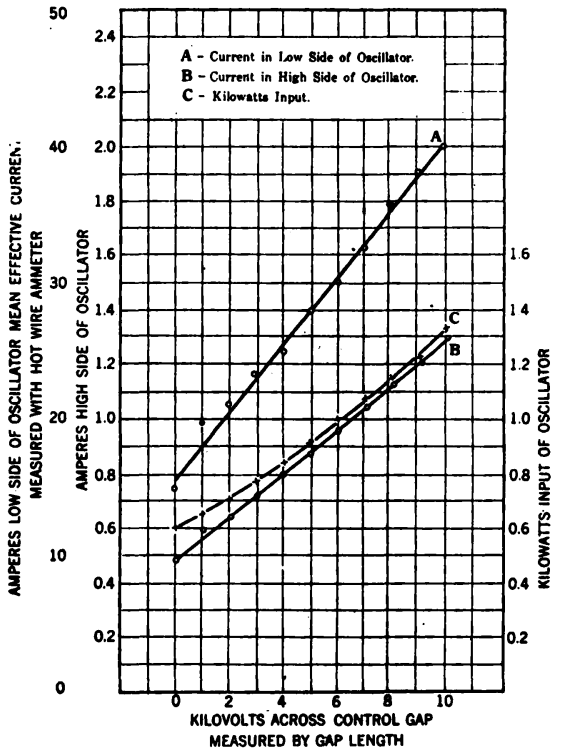

Fig. 6

Shirt-circuit characteristics of a 125-kv. oscillator. Top curve (A) is the relation of kilovolts across the control gap versus the effective current in the low side of the coreless transformer when the high side of the coreless transformer is short-circuited. Bottom curve (B) is the relation of the kilovolts across the control gap versus effective amperes on the high side of the coreless transformer. The current was measured by hot-wire meter. The middle curve $(C)$ is the relation of the kilovolts across the control gap versus the kilowatt input of the oscillator measured on the 60-cycle side.

set at 6000 volts. Two or three full-voltage sparks occurred every half-cycle. This materially increases the average current in the oscillator. With the air blast playing on the gap the number of sparks per half-cycle vary according to the length of control gap.

The curves of Fig. 6 give a measure of the oscillating currents in the high and low-tension coils of the oscillator at various settings of the control gap, the high-tension coil of the coreless transformer being short-circuited. The values of the control 
gap were obtained by calibrating the gap with 60 -cycie voltage. The values of current increase with the control gap. This increase is not directly proportional, as the resistance of the spark increases with the length of control gap, causing more rapid damping of the oscillations of each wave train.

The no-load characteristic is shown in Fig. 7, curve $A$. The normal voltage rating of the oscillator, $125 \mathrm{kv}$., is obtained at no-load with a control gap setting of $5 \mathrm{kv}$. which is less than

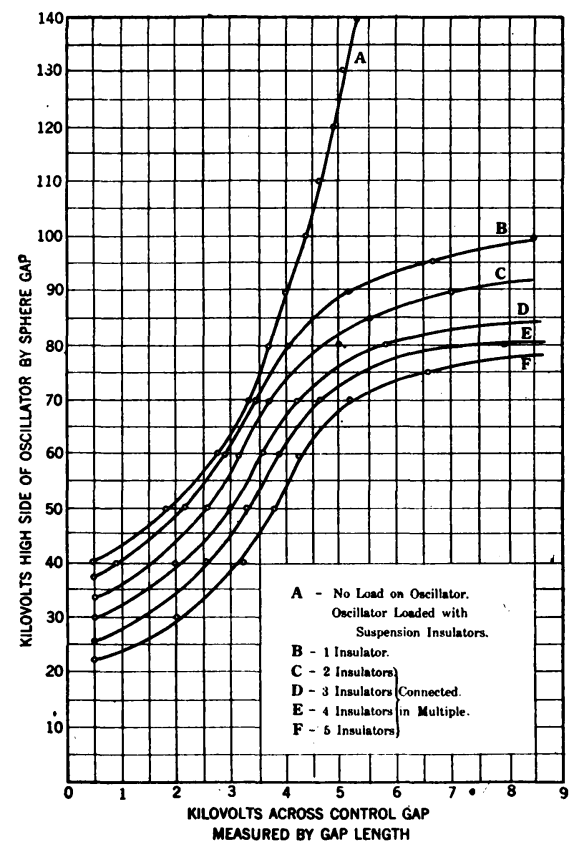

Fig. 7 Voltage generated by the $125-\mathrm{kv}$. oscillator in terms of control gap setting. Top curve
(A), no load on the coreless transformer. Second curve (B), load of one suspension insulator. The third curve (C), load of two suspension insulators in multiple. The fourth curve (D), load of three suspension insulators in multiple. Fifth curve (E), four suspension insulators in multiple. Sixth curve (F), five suspension insulators in multiple.

half the available voltage. Curves $B, C, D, E$, and $F$ were taken with varying numbers of suspension type insulators connected in parallel to the terminals of the oscillator. With only one insulator connected, the arc-over voltage of the insulator is $85 \mathrm{kv}$. This arc-over voltage decreases when more insulators are added in parallel, due no doubt to the combined effects of the local oscillations coming from the corona on the surfaces of the parallel insulators and the difference in the arc-over volt- 
age of the several insulators. With five insulators, the arcover voltage measured by the sphere gap was $77 \mathrm{kv}$. These curves are practically parallel, and their different locations are due to the change of voltage ratio of the coreless transformer caused by the capacitance and corona at the insulators.

The effect of this load on the regulation of the oscillator is illustrated in Fig. 8, which shows the voltage obtained with varying numbers of insulators connected to the oscillator while

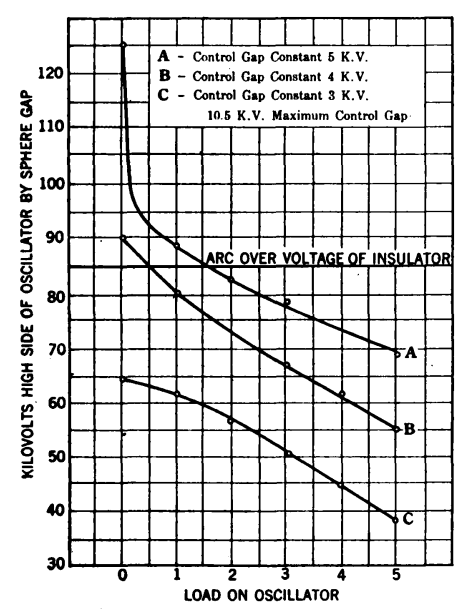

NO. OF SUSPENSION INSULATORS IN MULTIPLE

FIG. 8

Voltage regulation for variable loade with three different settings of the control gap on the 125-kv. oscillator. In the first curve (A) the control gap was held constant on a setting of $5 \mathrm{kv}$. and the load was increased from no insulators to five suspension insulators in multiple. At the addition of the second insulator the voltage was reduced slightly below the arc-over voltage of the insulator. Curve B is for a 4-kv. setting of the control gap, curve $C$ for a $3-k v$. setting. The maximum possible setting of the control gap in this oscillator is $10.5 \mathrm{kv}$.

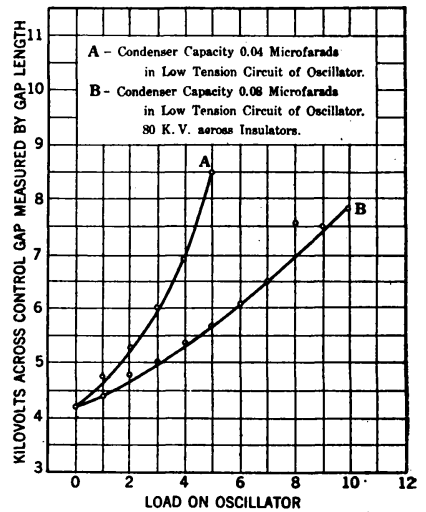

NO. OF SUSPENSION INSULATORS IN MULTIPLE

Fig. 9

Curves showing the gain in kilowatt capacity by increasing the capacitance of the condenser in a 125-kv. oscillator. Curve $B$ shows that the load can be practically doubled by doubling the capacitance to $0.08 \mathrm{mf}$. There was generated constantly for all values of load and control gap, a voltage of $80 \mathrm{kv}$. across control gap, a voltage of $80 \mathrm{kv}$. across the arc-over voltage of the insulator but sufficient to give extremely heavy corona.

maintaining the control gap constant. The voltage drop amounts to about 40 per cent from no-load to full-load, five insulators corresponding to full load for the condenser used in the oscillator.

The number of insulators that can be tested in multiple is directly proportional to the capacitance of the condenser in the low-tension circuit of the oscillator. This is illustrated in Fig. 9. By doubling the capacitance, the number of insulators that can be tested is increased from five to ten. The addition 
of çapacitance to the oscillator lowers the frequency so that the output of the oscillator is limited by the minimum permissible frequency. The output can also be increased by raising the voltage applied to the condenser. However, the voltage necessarily increases more rapidly than the number of insulators that can be tested so that the more efficient way to increase the output of the-oscillator is to increase the capacitance of the condensers.

Fig. 10 shows the load curve for the $125-\mathrm{kv}$. oscillator, with the insulators connected in multiple in strings of two in series. The control gap was set at $16.5 \mathrm{kv}$., which is beyond the rating

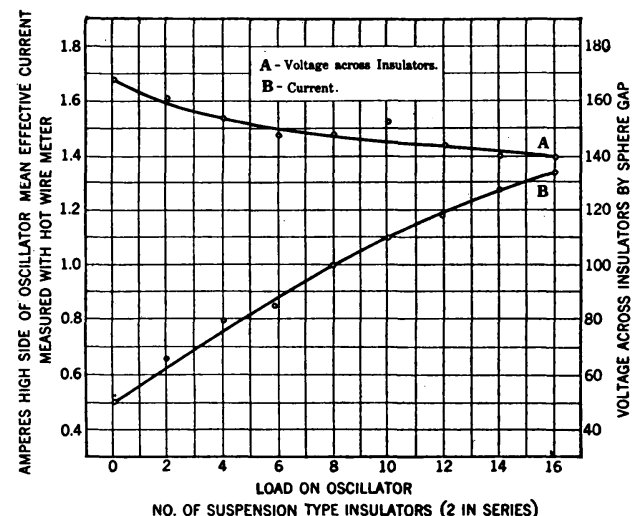

Fig. 10

In these curves the control gap was set at a constant value of $16.5 \mathrm{kv}$. with an air blast playing on it. It is an abnormal condition for the $125-\mathrm{kv}$. oscillator.

The load on the oscillator consisted of two suspension insulators in series and adding these as units. By so doing higher voltage was available than when one disk alone was used. The upper curve shows the fecrease in voltage on the insulators as the load is increased. The lower curve shows the iricrease in current in the insulators due to the high-frequency wave trains as the load is increa ed.

of the condenser supplied with the standard outfit. In addition, an air blast of about $\frac{3}{4}$ of a pound per square inch was used. The regulation in this case was 18 per cent drop from no-load to a load of 16 insulators. The current supplied to the insulators was measured with a hot-wire ammeter. This current increases with the number of strings of insulators added, about 50 milliamperes for each string added. The input of the low-frequency transformer was measured and remained constant at two kw.

\section{Natural Frequency of the Oscillator}

The frequency of the wave trains in.the low-tension circuit of the coreless transformer, having the secondary coil removed, 
was measured with a cymometer. The search coil of the cymometer was loosely coupled electromagnetically with the lowtension circuit of the corcless transformer. The capacitance of the cymometer was then varied until the maximum voltage was obtained which was indicated by a small lamp. This frequency is 220,000 cycles per second. The high-tension coil of the coreless transformer was then replaced and the sphere gap opened beyond the value which would allow a discharge to take place. The two frequencies of a close coupled circuit were then obtained which were 238,000 and 508,000 cycles per second. With a load of five insulators on the oscillator only one frequency could be detected which was 360,000 cycles per second. The reduction in maximum frequency from 508,000 cycles per second to 360,000 cycles has apparently no practical bearing on testing. If the higher frequency were prominent it should lower the spark voltage. As a matter of fact it has just been shown that the contrary condition exists, increasing the load lowers the equivalent sphere gap.

Setting aside the possible effects of local surges between the parallel insulators, the change in natural frequency, as measured by the cymometer, has the effect, if any, of having increased from the minimum value of 238,000 to 360,000 cycles per second. There is no question at issue at present in this matter of frequency and voltage measurement. It is admitted that the theoretical problems, as a whole, are complex. There is involved dielectric spark lag for jump sparks and creepage sparks, and a consideration of each as it is affected by frequency, wave front, logarithmic decrement, energy in the corona, potential gradient, etc. All of these things are beside the point and beyond the scope of this paper. The same problems apply to 60-cycle circuits but the advocates of 60 -cycle testing of insulators do not bring them into the discussion. The point is this: we are not directly concerned with the voltage which causes an insulator on a line to fail and thereby interrupt the service and damage the apparatus. The insulator must not fail. An insulator may pass a 60 -cycle test but fail on a sparkover test from the oscillator. They are probably never strained in use on the line with a voltage at 60 -cycles because their factor of safety places the operating voltage at a relatively small fraction of the arc-over voltage. When they are strained by voltage it is a high-frequency impulse or wave train very similar in form and natural frequency to the wave trains generated by 
PLATE XLV.

A. I. E. E.

VOL.'XXXIV, NO. 5

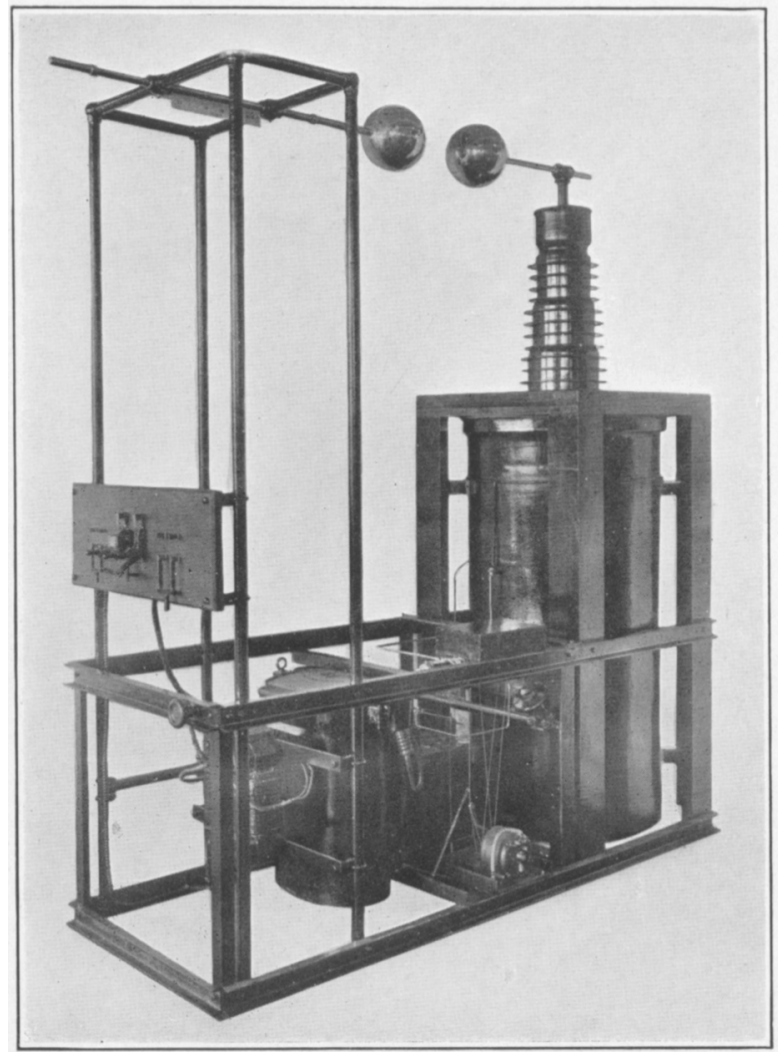

FIG. 11

[CREIGHTON]

The 250-kv. high-frequency oscillator. A small switchboard is mounted on the frame of the grounded sphere. Just below is a wheel for regulating the control gap. Above is the scale giving the value of kilovolts for the different settings of the sphere. Back of the scale giving the value of kilovolts for the different settings of the sphere. Back of the to the right in the foreground is a small motor belted to the revolving wheels of the control gap. Back of the motor are the electrostatic condensers and to the right is a large coreless transformer supporting one sphere and having its other terminal grounded. 

the oscillator. The wave trains in a transmission circuit will vary over a wide range of frequency but they will not differ as much in frequency from the oscillator as they do from 60 cycles, by more than a thousand times.

\section{250-Kv. High-Frequency Oscillator}

The general appearance of this oscillator is shown in Fig. 11, the construction being similar to the $125-\mathrm{kv}$. oscillator. The

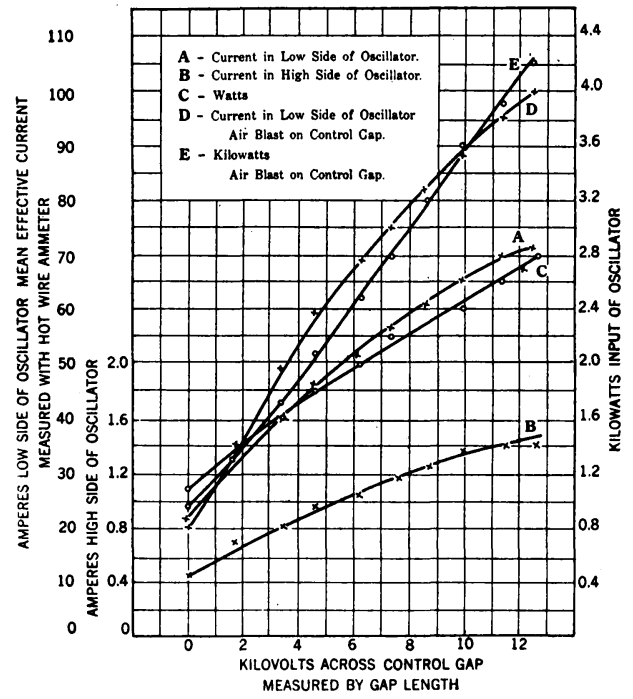

FIG. 12

Short-circuit characteristics of a 250-kv. high-frequency oscillator with the high side of the coreless transformer short-circuited. The following relations are given: Kilovolts across control gap versus current in low side of coreless transformer (Curve A). Kilovolts across control gap versus current in high side of coreless tranformer (Curve B). (Smaller values of ampere scale to the left.) Kilovolts across control gap versus kilowatt input of oscillator (Curve C). Scale to the right.

An air blast was then played on the spark in the control gap. Curve D corresponds to Curve $A$ under this new condition. Also Curve $E$ of the kilowatts with the air blast on corresponds to Curve C. It will be noted that the air blast increases both the current and kilowatt input by producing a greater number of wave trains, as illustrated in Fig. 5 .

coupling between the high- and low-tension coils of the coreless transformer, however, is not as close, as more insulation is necessary between coils. The short-circuit characteristics are shown in Fig. 12. These are similar to those obtained with the $125-\mathrm{kv}$. set. The effect of an air blast on the spark in the controlgap in increasing the current in the oscillator coils and the watts input, is shown in curves $D$ and $E$. The current is increased about 40 per cent. 
Fig. 13 shows the no-load characteristic. For small values of control-gap setting the air blast increases the voltage obtained on the high side of the oscillator. This is probably due to the cooling effect of the blast raising the spark potential of the control gap. For higher values of the control-gap setting this effect becomes less noticeable.

Curves $B$ and $D$ show the effect of connecting to the oscillator a 70-kv. oil-filled transformer bushing. These curves begin to bend over at about $230 \mathrm{kv}$. owing to the rapid increase of the brush discharge as the arc-over voltage of the bushings is approached. This arc-over voltage is about $245 \mathrm{kv}$.

\section{PART II}

26. The Manufacture of Electrical Porcelain

In the order in which the work described in this paper was done, various experiences in testing porcelain with the oscillator should come next, but to understand the results of the experiments a knowledge of the characteristics of porcelain in its various stages of manufacture is quite essential. Therefore the processes of manufacture will be mentioned before continuing with the experiences of testing.

The object of this part of the paper is to endeavor to bring together the elements of scientific ceramics as they relate to porcelain for electrical purposes, eliminating all products pertaining to various other industries.

The endeavor is to draw out of this mass of literature only the parts that seem to relate to porcelain for electrical purposes. The object is also to bring the subject of ceramics far enough into the field of electrical engineering to arouse an interest in the subject as it relates to our work. It is hoped to accomplish this by a cursory review of the subject, such as may be made in the time at my disposal, and in this review give references on the subject to the student who is desirous of making a further study into the details.

On the side of ceramic engineering it is hoped to stimulate a sufficient interest to obtain help and place the ceramic engineer in a better position to help himself by giving definite methods of electrical tests and making definite statements of our requirements of porcelain parts used as insulators. The natural aim is to improve the integrity of the insulators. Simply put, it is desirable to have an insulator which will never puncture nor break and if the potentials from lightning get beyond its dielec- 
tric strength the insulator must spark over through the air without puncturing the porcelain. To attain this end, many complex and unsolved problems must be considered. In this paper we are interested mostly in the problem of the production of a desirable insulator rather than in methods of protection which may be used to prevent high potentials occurring on an insulator.

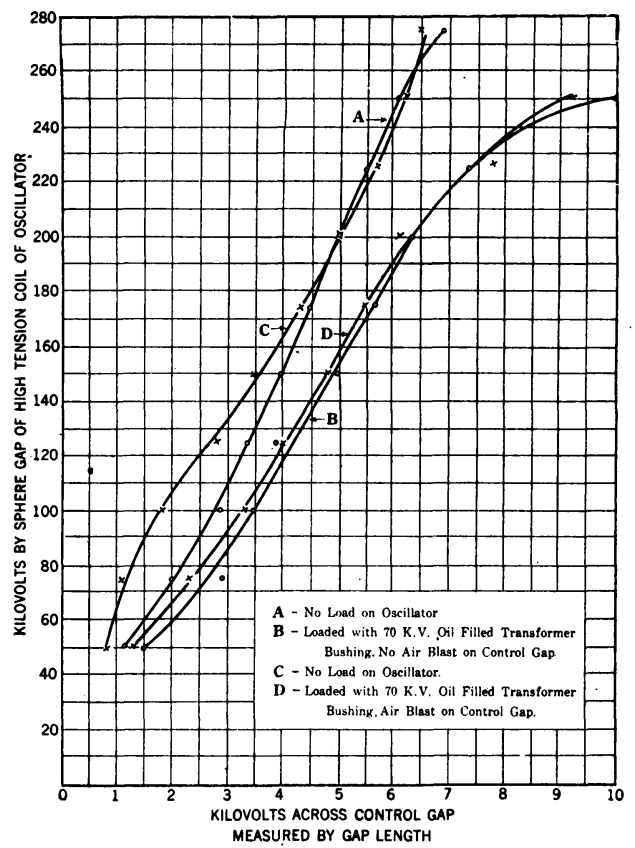

FIG. 13

The relation of kilovolts across the control gap to the kilovolts on the high-tension side of the coreless transformer as measured by sphere gap.

Curve A, no load on oscillator: Curve B, loaded with one 70-kv. oil-filled transformer bushing.

An air blast was then played on the spark of the control gap and curves $C$ and D were taken. Curve C, noload on oscillator, as in Curve A. Curve D, same load as in Curve B. It will be noted that except at low values of control gap the air blast had very little effect on the voltage generated. In general, with the revolving wheels for control gap, the air blast will change the number of wave trains without changing materially the voltage.

\section{Desirable Qualities in a Porcelain Insulator}

1. It shall be mechanically strong in compression and tension.

2. It shall be tough, not brittle or fragile.

3 . It shall be non-porous.

4. The porcelain shall be without appreciable cracks, laminations, cavities, conducting flaws, or air pockets.

5. It shall be of a fair, uniform dielectric strength. 
6. It shall have a permanent glaze without cracks, roughness or checks to hold dirt in the surface. It is desirable to have the glaze as non-hydroscopic as it is possible to obtain without sacrificing other factors.

7. Incidentally the coefficient of expansion of the porcelain should be low in order to permit of sudden changes of temperature due to the weather conditions.

8. The parts should be held together with non-changeable cement.

9. In the matter of design the general rule to follow should be to keep the distance between the metal electrodes as great as the mechanical strength will permit. In general this rule calls for thicker porcelain than can be economically manufactured.

10. The design should be such that the air around the insulator is weaker to puncture than the thickness of the porcelain even under super-spark potentials.

11. The design should be such as to give a relatively long drip space for water so as to hold a high value of spark-over potential during a rain.

12. For dusty countries extra lengths of creepage surface should be provided.

It is far easier to state what is desired than it is to make definite recommendations of how the desiderata are to be obtained. Every possible avenue of investigation should be tried until the desired perfection of insulator is reached.

\section{Literature on Porcelain}

Most of the literature on ceramics treats of pottery from an artistic and historic standpoint. One must read hours to pick up a few grains of useful information on the electrical porcelain intended for engineering purposes. One long book, containing over 700 pages on the manufacture of ceramic materials, devotes only one-half page to electrical porcelain. The Encyclopedia Britannica devotes many pages to what can be seen on the surface of some specimen handed down from the nations of antiquity. These specimens range in technical skill of manufacture from the sun-dried pot, through the grade of soft porcelain, and finally to the most difficult, namely the art porcelain composed of kaolin, or china clay.

The writers on porcelain have not yet recognized that the modern electrical porcelain involves more attention to the form 
of the parts than the most fastidious Greek ever gave his. If in the ancient Greek art the curves were poor it displeased some of the cultivated eyes,- - that was all. If in modern electrical porcelain the curves are poor, thousands of people are deprived of light and power,-which might be conceded as a more serious matter.

Electrical porcelain is an art of the present decade, - an art in the making: The author has spent much time culling out of the massive literature on the civilization-old art some of the pertinent factors relating to electrical porcelain, and it is thought that such condensed information is of value to others who are interested.but have not the time or opportunity to cover the subject.

While making tests under new advantageous conditions the information has been brought to the attention of ceramic engineers, and it is hoped, through this system of checking, that inaccuracies regarding the porcelain manufacture in any of the essential parts have been avoided. The difficulties of getting definite information on porcelain will be fully appreciated only by those who have tried. In our own meetings we have even been advised as electrical engineers to leave this difficult subject to the particular man who fires the porcelain part. For the electrical engineer a cloud of mystery is thrown around this work. The desire to maintain trade secrets has obscured processes which are universally used. Either a knowledge of some of these processes must be furnished to the electrical engineer to intelligently interpret his electrical tests, or else the ceramic engineer must fully master the electrical problem of design and produce the finished satisfactory insulators. One naturally turns to the Proceedings of the American Ceramic Society for information. In the Annual Report of the Board of Trustees the statement is made that, "Our industries are most of them old, and most of them have been and still are administered upon mistaken policy of secrecy as a necessary condition of success. Very few practical ceramic chemists and works managers will tell what they know of their own branch of the industry."

\section{Dry Process versus Wet Process}

Dry Process Porcelain. We are not concerned herein with all grades of electrical porcelain. Porcelain for electrical purposes is divided into two quite distinct grades, known as dry process and wet process porcelain. As indicated by the names, they differ 
in manufacture mostly in the way the porcelain pieces are formed into the desired shapes. In the dry process, the raw mixture is in the form of slightly moist granular particles containing about 20 per cent of moisture by weight. These moist particles having the appearance of granulated or grated cheese, are made to cohere in a moment into a handleable soft mass by being subjected to a high mechanical pressure in a mold. This pressure, no matter how great, does not squeeze out the entrapped air between the particles and furthermore, under the usual conditions of firing the open pores still remain. As a result, dry process porcelain is electrically only about equal to air in its dielectric strength. To get mechanical strength, the thickness of the porcelain parts is usually great enough to give safe dielectric strengths of the order of a thousand volts. When the voltage impressed on this porous dry process porcelain is several thousand volts the potential gradient at sharp corners of the electrodes is sufficient to start a molecular bombardment of the air in the pores. As a result the porcelain becomes heated, its ohmic resistance rapidly decreases with temperature and there is added to the heat of corona, the $I^{2} R$ losses. If the dry process porcelain is used on high voltages it is used as a mechanical support but not as an insulator.

Wet Process Porcelain. The wet process porcelain is deposited in the form of a plastic cake, as will be described later, and although this cake becomes quite porous when it is dried out, the size of the pores, or the spacing between particles is much smaller than in the dry process piece; consequently these particles can be cemented together in the kiln by the flux when the temperature reaches the melting temperature of the flux. Looking at the condition from a slightly different standpoint, each grain of the dry process material is made up of many fine particles of the same size as in the wet process and each grain becomes fairly well cemented into a solid vitrified mass, but the separate grains of the dry process are vitrified together only in those touching points that are near enough together to be connected by the softened flux at high temperature. In the shrinkage many irregular masses are pulled slightly apart leaving not only open pores but open streaks which are easily observed with the naked eye by first soaking the porcelain piece in red ink, (or better still aniline stain in alcohol), and subsequently breaking the porcelain piece into fragments. 
30. The Ingredients of Electrical Porcelain

The three main ingredients of electrical porcelain are feldspar, clay and silica.

The feldspar constitute a large portion of granite rock. After the granite is crumbled a certain amount of free feldspar results. There are three feldspars which exist either separately or more or less mixed mechanically and chemically in the mines.

1. Potash feldspars, known also as common feldspar or the mineral orthoclase. It consists of potassium, aluminum, silicon, and oxygen. $\mathrm{K}_{2} \mathrm{Al}_{2} \mathrm{Si}_{6} \mathrm{O}_{16}$

2. Soda feldspars - a tersilicate of soda-a mineral known as albite or indianite. It contains sodium, aluminum, silicon, and oxygen. $\mathrm{Na}_{2} \mathrm{Al}_{2} \mathrm{Si}_{6} \mathrm{O}_{16}$

3. Lime feldspar or unisilicate of calcium-a mineral known as anorthite, consists of calcium, aluminum, silicon, and oxygen. $\mathrm{Ca} \mathrm{Al}_{2} \mathrm{Si}_{2} \mathrm{O}_{8}$. The most important of these three feldspars for electrical work is potash feldspar.

When the feldspars are disintegrated or separated into their respective constituent oxides they have the following chemical formulas and percentage of weight.

\begin{tabular}{|c|c|c|c|c|}
\hline & & Potash & Alumina & Silica \\
\hline $\begin{array}{l}\text { Potash } \\
\text { Feldspar } \\
\text { Soda } \\
\text { Feldspar } \\
\text { Lime } \\
\text { Feldspar }\end{array}$ & $\left\{\begin{array}{l}\text { Molecular properties. } \\
\text { Percentage weight.... } \\
\text { Molecular properties. } \\
\text { Percentage weight.... } \\
\text { Molecular properties. } \\
\text { Percentage weight.... }\end{array}\right.$ & $\begin{array}{l}\mathrm{K}_{2} \mathrm{O} \\
16.9 \\
\mathrm{Na}_{2} \mathrm{O} \\
11.8 \% \\
\mathrm{CaO} \\
20.1 \%\end{array}$ & $\begin{array}{l}\mathrm{Al}_{2} \mathrm{O} \\
18.4 \\
\mathrm{Al}_{2} \mathrm{O}_{3} \\
19.6 \% \\
\mathrm{Al}_{2} \mathrm{O}_{3} \\
36.8 \%\end{array}$ & $\left\{\begin{array}{c}\mathrm{Si} \mathrm{O}_{2} \\
64.7=100 \% \\
\mathrm{Si} \mathrm{O}_{2} \\
68.6=100 \% \\
2 \mathrm{SI}_{2} \mathrm{O}_{2} \\
43.1=100 \%\end{array}\right.$ \\
\hline
\end{tabular}

\section{Clays}

The two clays used as main constituents of porcelain are ball clay, and china clay or kaolin. The chemical analyses given of the clays differ from each other very little yet the properties or characteristics of these clays in the practical work of manufacture differ greatly.

The important physical quality which distinguishes the clays is their degrees of plasticity. The physical and chemical conditions which give the clays their plasticity seems to be a mooted question still among the ceramists. The particles of clay are exceedingly small. They are sometimes spoken of as colloids. The plastic clay has an unctuous greasy feel when rubbed. 
Although the cause of plasticity cannot be given, the quality itself is familiar. By plasticity, as used by ceramists, something more is meant than that quality of allowing a change of dimensions by kneading while maintaining the particles in cohesion such as exhibited by light bread dough. There is meant or implied that after the water, mixed with the clay to render it plastic and pliable, is dried out, the particles of clay will not crumble into dust but will remain in a sufficiently solid condition to be handled without breakage. A variation in the relative weights of water is needed to render the clays from the several different mines plastic. The china clays and kaolins have not a high degree of plasticity and therefore there is added to them ball clay which has the highest degree of plasticity. A piece of soft ball clay can be rolled into a long round coherent thread or rope without breaking. After the raw porcelain is dry it must retain sufficient coherence not only to hold itself together but also the ground up particles of feldspar and flint, neither of which possess sufficient plasticity to give much aid. All the clays lose their plasticity after being heated above a few hundred degrees centigrade. It should be recognized that plasticity and coherence are among the most important qualities of raw porcelain. Many of the flaws are developed in an incipient degree before the porcelain goes to kiln.

The word kaolin is a corruption of a Chinese name for the locality where the china clay was obtained for the ancient industries. Kaolin, the clay, has an essential ingredient the mineral kaolinite. The formula for kaolinite is given in several forms. It seems evident that the molecular structure varies greatly according to the material from which the kaolinite was formed.

Kaolinite is composed of hydrogen, aluminum, silicon, oxygen, and water of composition. The chemical formula is written as follows: $\mathrm{H}_{2} \mathrm{Al}_{2} \mathrm{Si}_{2} \mathrm{O}_{8}+1 \mathrm{H}_{2} \mathrm{O}$.

When the kaolinite is considered from the standpoini of the resulting product, after it is disintegrated, its composition is given in terms of its oxides, namely alumina, silica, and water, in the formula $\mathrm{Al}_{2} \mathrm{O}_{3}, 2 \mathrm{Si} \mathrm{O}_{2}$, and $2 \mathrm{H}_{2} \mathrm{O}$. The proportion of each of these is given in percentage directly below the corresponding formula.

$\begin{array}{llll}\text { By formula } \ldots \ldots \ldots \ldots \ldots \ldots \ldots & \begin{array}{c}\text { Alumina } \\ \mathrm{A1}_{2} \mathrm{O}_{3}\end{array} & \begin{array}{c}\text { Silica } \\ 2 \mathrm{Si} \mathrm{O}_{2}\end{array} & \begin{array}{c}\text { Water } \\ 2 \mathrm{H}_{2} \mathrm{O}\end{array} \\ \text { By relative weight.............. } & 39.8 \% & 46.3 \% & 13.9 \%\end{array}$


Kaolinite is derived from the disintegration of feldspar in granite rocks which is brought about by the action of the elements, air, water and temperature.

Granite consists of the minerals orthoclase or microcline, mica, and quartz.

Silica, $\mathrm{SiO}_{2}$, silicon dioxid, silicic oxide, quartz, flint, crystalline silica and sand are all used synomymously in relation to porcelain manufacture. All of these materials are nearly pure silica in slightly different molecular form and different in the nature of their small impurities. In general this constituent of porcelain is called flint although in many porcelains ground-up quartz sand is used. Of the other silica materials which are not used but which are high in silica there is the precious stone opal which has a higher content of water, infusorial earth, and float sione.

If we turn to the chemistry on these three materials we learn that the feldspar is used as a flux on account of its content of potash or soda. Flint, and quartz alone are very refectory materials and are not affected by the temperature of $1350 \mathrm{deg}$. cent., the approximate value of the temperature of a porcelain kiln. Quartz is not attacked by acid with the exception of hydrofluoric. Boiling alkalin solutions scarcely affect it. Flint, however, dissolves more readily in boiling solutions of the alkalin hydroxides. All the varie iies of silica, however, when heated to redness with the alkalis, such as potash $\mathrm{K}_{2} \mathrm{O}$ or the alkalin, carbonites, combine with the bases forming silicates which enter into fusion at a high temperature and solidify to a vitreou:; mass on cooling.

It is this solvent action of the potash of the feldspar on the: quartz or flint which produces the solid porcelain mass. The: greater the quantity of feldspar or flux the greater the tendency' to vitrify. Combinations of clay and silica containing very. little flux require extremely high temperatures to vitrify-. several hundred degrees above the value usually obtained in the porcelain kiln. A definite idea of the softening temperatur!: of the different compounds is furnished by the Seger cone; which are used to measure the vitrifying condition in the kilns. These cones consist of the different minerals made up in a tri. angular pyramid, having a width of $9 / 16$ in. at the base, $1 / 16$ in. at the top and an. over-all height of $2 \frac{7}{8}$ in. The catalogut: of the manufacture of the cones gives a complete list of ingredi.. ents with the corresponding temperatures they represent. 
Several of these cones, Fig. 14, differing by one number, are placed side by side as a unit, and are located in different parts of the furnace where it is desired to measure the temperature. As the temperature reaches the melting point of each cone it deforms by bending over like a wilted plant. These cones under the high temperatures of the furnace droop to different degrees and the one that is not deformed at all represents the temperature or limit of the vitrifying tendency of the furnace.

To obtain a porcelain which will vitrify at different temperatures it is in general necessary only to change the content of potash or soda. It may be done also by using a feldspar containing both potash and soda in combination as the two together seem to have a greater solvent action than either one alone.

Lime feldspar is used not at all or only sparingly. Lime is one of the chief ingredients of common glass and apparently has undesirable qualities in porcelain.

\section{The Proportion of Different Minerals for Porce- lain and the Difficulties in Obtaining and Maintaining these Proportions Due to the Geological Conditions and Methods of Mining}

A standard mixture for porcelain for testing purposes is given as feldspar 20 parts by weight, quartz 30 parts by weight, kaolin 50 parts by weight. In Bulletin 53 of the Government Bureau of Mines, Mr. A. S. Watts states that the role of kaolin in all pottery mixtures is that of a plastic bond. It continues to hold the material together through the drying process. In firing, the kaolin by its high refectory value and its resistance to the solvent action of the feldspar, enables the mass to retain its form although the particles of kaolin may be enveloped in fluid feldspar so completely that the mass becomes translucent and appears homogeneous.

The ingredients of porcelain as received in the mineral state by the porcelain manufacturers are liable to considerable variations both in their chemical contents and in the molecular form in which they exist. One cannot understand the difficulties of porcelain manufacture without a comprehension of the methods and conditions of mining the minerals. The change of material sold by the same name and giving the same chemical analysis in a porcelain factory is usually not carried out within a year after the change is contemplated as it requires a very long time to learn the methods of handling the new material 
PLATE XLVI.

A. I. E. E.

VOL. $X X X I V$, NO. 5

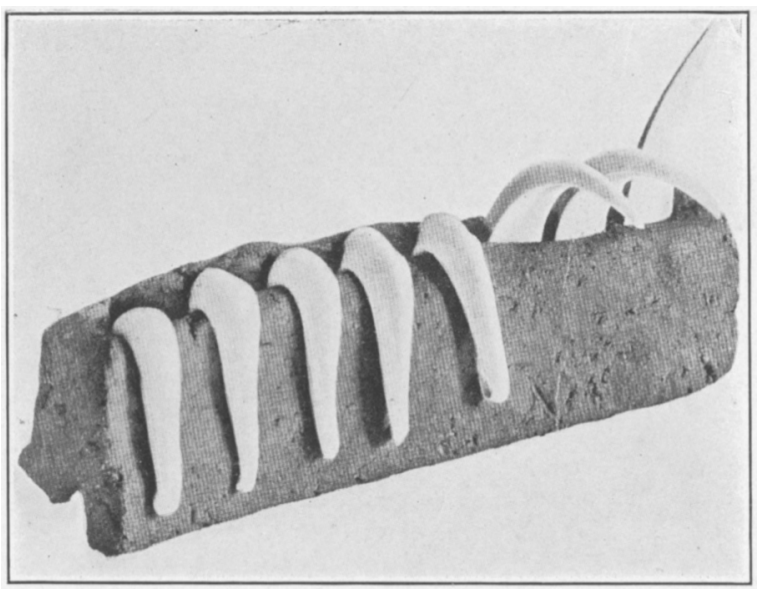

FIG. 14

[CREIGHTON]

Fired Seger cone showing the five lower cones entirely wilted, two cones part way down and one cone still standing almost vertical. (Bulletin 53. By courtesy of U. S. Department of the Interior.) 

in the many different forms in which electrical porcelain parts are made. In Bulletin 53 on mining and treatment of feldspar and kaolin in the Southern Appalachian region, already mentioned, Mr. Watts devotes 170 pages to the study of this subject from many standpoints. He described deposits of feldspar which are in all grades of decomposition approaching kaolin. Before such material can be used it is necessary to separate the kaolin clay from the semi-kaolinized feldspar or otherwise it is necessary to have a uniform mixture which can be depended upon after the proper mixture of other clays and feldspar is determined by experimentation. There is always a considerable amount of silica in one form or another in these deposits of clay and there are more or less impurities such as oxides of magnesium, calcium and iron. There is often the mixture of minerals washed in from 'the surface during the time of mining and incidental deposits and streaks of other materials which have found their way into the mass during the time of their geological formation. Some of these foreign materials may be picked out in lumps by hand. There is usually present more or less mica. Indeed some of the mines are operated for the mica leaving the clays only as a by-product. The mica must be removed. The methods of refining the clays differ somewhat according to the nature of the deposits but the general plan followed is by separation by difference in weight of the particles. When the kaolin is formed by the decomposition of feldspar it apparently forms a colloid of extremely small diameter. This fact is utilized to separate the fine clay from the coarser quartz sand and feldspar by floating it in water. If a mass of this material is stirred up in water the heavier particles will immediately settle to the bottom and the lighter particles can be floated off. It is by means of these settlings and floatations in water that the fine clay is separated from the coarser materials and is finally dried and thus prepared for shipment. If there exists in this mechanical mixture small particles of flint or feldspar they are of course carried over with the fine clay. Screens are used to separate the mica. In the final concentrating tank there is sometimes introduced a floculator in the form of alum in order to hasten the settlings of the very fine clay particles.

With all these possibilities of impurities arising in the process of mining, with all the different molecular forms which this material may take and all the variations which may occur from one part of a mine to another, and with the impossibility of 
getting any chemical analysis in general on which a practical porcelain manufacturer can depend, it will be appreciated that the difficulties in getting and maintaining the proper mixtures in a porcelain factory are very great.

\section{Some of the Salient Points in the Factory Process}

The points in which we are interested in general are those which have a direct bearing on the final product as an insulator. After an examination of the dielectric strength of porcelain from four different manufacturers, all of which use different clays, and therefore vary in their chemical content to a certain extent, it would seen that within a considerable range, the minerals, as such, have little bearing on the dielectric strength. The minerals in regard to their ease of working and uniformity may have considerable to do with the final product in avoiding cracks, flaws, laminations, and other like mechanical accidents of manufacture.

A certain quantity of china clav, ball clay, fledspar, and flint are ground separately to impalpable powder and are weighed out and thorwn into a large tank, known as an agitator, in which there is a motor-driven paddle which constantly keeps the maierial mixed up. The liquid consisting of these fine particles suspended in the watcr, of the consistency of heavy cream, is known as "slip." There is the possibility of some slight difference in uniformity due to difference in weight of the particles and this is the first possibility of non-homogeneous material. A porcelain manufacturer states, however, that the probabilities are comparatively slight since all the material is made fine enough to pass through a certain size sieve-100 to 200 mesh per inch.

After being mixed in the agitator tank, the slip is pumped into filter presses in which the water is forced out through canvas, leaving the fine materials deposited in the form of soft wet cakes. In this deposition there is a tendency for the coarser material to segregate from the finer materials. Since this filter press is worked under considerable hydrostatic pressure and the fibres of the canvas must finally wear out, there will be occasionally here and there a fine cotton fibre which finds its way into the mass of clay. This fibre, carbonized in the firing, will form a ready path of puncture.

The cakes of deposited raw porcelain which come from the filter press are thrown in a pile and hammered down by a large 
mallet. This material is then sliced off by means of a thin wire having a wooden handle at each end and the pieces are thrown into a pug mill. Human hairs, threads, and other carbonacious substances occasionally find their way into the porcelain during this period and subsequently cause an electrical flaw.

The pug mill consists of a cylindrical receptacle about five feet high. In the center of this cylinder there is a vertical shaft from which extend horizontal arms or blades formed like the propeller of a boat. The blades cut through the plastic mass and constantly squeeze out the air and force the material downward. At the bottom is a horizontal opening, four to eight inches in diameter, out of which the soft mass is squirted by the pressure exerted by the blades above, or by an auger near the exit. It then has a consistency barely sufficient to hold its form. As this plastic mass comes from the pug mill it is cut off into cylindrical pieces by means of a fine wire. The proper manipulation of the material in the pug mill is considered of very great importance as it is possible to leave the clay in a condition in the pug mill which will subsequently cause a sufficient defect in a porcelain part to condemn it for practical use. The pug mill is used to remix the constituent parts so that the materials will be uniformly distributed through the entire mass. To obtain this end, it is sometimes necessary to put the raw porcelain through the pug mill more than once and, as an interesting incident, it is necessary to add more water to the mass each time it goes through, to replace the loss due to heating which results from the friction of the revolving blades against the plastic mass. Before the raw porcelain is thus mixed in the pug mill it is possible to pick out spots where even inexperienced persons can recognize non-homogeneous conditions by the feel and plasticity of the soft mass.

In the usual molded process the soft plastic mass as it comes from the pug mill is formed or "jiggered" into a "blank" of the approximate shape which it is finally to have and the "blank" is then left to partially dry. It is sometimes jiggered into a plaster paris mold. As the moisture evaporates from the surface the material shrinks to a certain extent and since the outer surface must always be drier than the central parts there must always exist a tendency for cracks to form on the surface. This is prevented by not having the plastic mold too dry, by keeping the design dimensions within reasonable limits, usually 
within an inch of thickness, and by controlling the moisture content in the atmosphere of the drying room. Where a drying room is full of fresh samples the humidity of the room is high and consequently the drying will be slow. In times of slack work where a less number of pieces are drying there will be more rapid drying and consequently a greater danger of damage through shrinkage. There will be a difference due to the humidity of the seasons.

When the material becomes fairly dry it should have sufficient strength to allow it to be handled in packing it in the saggers ready for firing and, in many cases, sufficiently strong to allow of turning in a lathe. Herein comes an important factor of plasticity and coherence in choosing the ingredients of the porcelain.

\section{G.LAzING}

After the porcelain pieces have become well air-dried they are glazed. The usual glaze consists of a material essentially the same as the porcelain except that a higher percentage of flux is used which makes the glaze melt and run over the surface at a temperature which barely vitrifies the body of the porcelain. The flux of the glaze unites with the porcelain body on the surface and forms a chemical combination which makes a gradation from pure glaze to pure porcelain.

The glaze is put on the surface by means of dipping. The fine material in water in the tank is often kept in suspension by means of a stirrer and the dry surface of the porcelain absorbs the water and thus produces a thin coating of the glaze material on the surface in a powdered form. The moisture thus introduced in the material is then allowed to dry out and if the whole surface of the porcelain has been glazed it is necessary to scratch off the powder of the glaze where the porcelain piece will rest on the sagger or otherwise the porcelain piece after firing would be glazed solidly to the sagger. The colors of the glazes are produced by different oxides.

In other kinds of pottery there are other glazes and other methods of glazing used which have no application to any of the electrical porcelains. In some of the earthenware materials glazing is produced by throwing common salt, $\mathrm{NaCl}$, onto the red-hot material. The chlorin is given off and the free sodium combines with the earthenware material and thus forms a glaze. In some work known as biscuit porcelain, used especially in art work, the porcelain is given a preliminary firing at a high tempera- 
ture with no glaze on it. It is subsequently covered with a glaze requiring a much lower temperature to melt it. Such a glaze will often have a difference of expansion relative to the porcelain body and there is, involved, therefore, a great tendency to check or crack, known technically as " crazing." Electrical porcelain, in general, is fired only once and glazed at that time or not at all.

\section{FIRING}

After the clay has been thoroughly air-dried and possibly baked to a temperature of 110 degrees to drive off all the free moisture it is packed in saggers which are yellowish, rough earthenware dishes, in the material of which there is a very small content of flux and therefore a much higher melting point than the porcelain parts which they contain. The usual saggers are cylindrical in form, a foot or two in diameter and high enough to accommodate the porcelain pieces. They are open at the top. These saggers containing the porcelain parts are stacked in the furnace one on top of another, making a column from the base of the furnace to the top. This column of saggers is called a bung. The furnace is completely filled with these bungs, leaving only room here and there above the many openings in the base of the kiln for the heat flames to rise as uniformly as possible through the entire mass. The usual kiln is bottle-shaped. Around its base at equal distances are eight fire-places which feed into a radial flue running to the center with several vertical openings into the kiln.

The fires are then started, using either a good grade of coal or gas, and the temperature is gradually brought up for hours to a value in the neighborhood of 1310 to $1360 \mathrm{deg}$. cent. After reaching the maximum temperature it is usual to hold the temperature for several hours in order to let the heat soak uniformly throughout the mass of bungs. The fires are then allowed to die out and the kiln cools, the whole process taking several days depending on the size of kiln. The fire brick door is knocked out, the saggers are unstacked and the porcelain parts taken out and examined for flaws. The porcelain parts which pass this visual inspection are then ready for the electrical tests.

35. A Review of the Processes of Porcelain Manufacture which have to do with the Dielectric Strength of the Porcelain the Choice of Ingredients as Affected by Firing

The firing temperature of a furnace is fixed by experience with a certain mixture of porcelain ingredients. It is assumed that 
each mix of this material is the same as the previous one on which the experience was obtained. Necessarily then whatever be the chemical contents of the bins marked china clay, ball clay, flint, and feldspar, this material should be uniform. If these materials vary in chemical composition there is no definite way of determining it until the firing is completed and all the damage is done. If the flux is too small in quantity the porcelain may be found under-fired and porous; on the other hand, if the flux is too great in quantity the porcelain parts may be over-vitrified and therefore brittle and they may even be warped entirely out of shape by becoming too soft. An important point in this regard seems to be to keep enough solid material in the form of either alumina contained in the clay or relatively large particles of flint so as to hold the body of the porcelain in form during the firing. The desire of the ceramist is to obtain a body and flux which will have a wide range of temperature between the lowest temperature which will cause a softening of the flux and the lowest temperature which will cause a warping of the porcelain due to its own weight. The initial ingredients are then of great practical importance to the ceramist in obtaining a useful article, when the firing is completed, both in form and dielectric strength. Porous porcelain will absorb moisture and will therefore have its insulating value greatly decreased. As already stated, there is always some surface on the porcelain piece which is not vitrified and it is through this surface that moisture may subsequently enter the whole body of porous porcelain. If the porcelain is over-vitrified it will be brittle and although its dielectric strength may be excellent it is liable to damage in shipment or installation due to its fragility.

\section{Homogeneity of Structure in the Plastic Form}

Assuming then a proper choice of the mixture, the next important step is the conditions of the pug mill. The material must be made thoroughly homogeneous when it leaves the pug mill. Otherwise there will be a separation into laminations or local spots that are not fully vitrified together. If many porcelain parts of irregular form are broken up after they have been punctured electrically laminations will irequently be found in the material. It is stated that some of these laminations really originated at the time the clay was passed through the pug mill. As the raw porcelain in flat cakes comes from the filter press it will frequently contain a layer of flint. This layer of flin $\iota$ lacks 
plasticity and if not thoroughly mixed with the ball clay in the pug mill the raw porcelain in drying will open in a lamination or crack at this surface of weak plasticity. Where the lamination is perpendicular to the lines of electric force very little weakening in the dielectric strength of the porcelain piece takes place, but where this lamination occurs at an angle or parallel to the lines of electric force the porcelain part usually lacks enough dielectric strength to make it useful.

\section{Flaws Developed During the Process of Drying in AIR}

Occasionally it happens that changes of moisture in the atmosphere, especially in the dry season which is the winter ime in the cold countries, will cause a shelf-full of drying porcelain or a few on the end of the shelf to dry with such great rapidity as to introduce local internal mechanical strains in the body of the solidifying material. It is therefore of great value to study the rate of change of plasticity and shrinkage at the different states of drying. Bourry (Treatise on Ceramic Industries-D. Van Nostrand Co.-) shows by the curves which follow that the greatest contraction takes place in the clay body at the time it is changing from a soft plastic condition to a solid form. Subsequently, although the moisture is still considerable, the shrinkage is very much less. It is therefore during the early stages of drying that the greatest care must be taken to prevent a rapid evaporation from the surface of the porcelain. Subsequently much less care need be taken and more haste is permissible.

\section{THEORY OF DRYING}

Bourry divides the drying of raw porcelain into three periods. The prastic material consists of solid particles and water. The solid particles are all small but vary greatly in dimension from the very fine particles of clay to the coarsest particles of flint. Each one of these particles is surrounded by a film of water held in position by capillary attraction. This gives a certain fluidity or ease of movement of one particle over another and is one of the factors which accounts for plasticity. In this soft condition it can be stated that there is a certain definite volume of solid material and a certain volume of water. As the drying proceeds, the film of water between particles becomes thinner and the particles approach each other, which gives the general shrinkage or contraction of the body. 
When these particles come into contact there can be no further shrinkage although there is still a considerable percentage of moisture in the mass. During this second stage when the particles are coming into contact the volume of moisture is decreasing at a greater rate than the shrinkage. It is probable that if all the particles were of exactly the same dimensions there would be a very definite cessation of shrinkage when the particles come into contact. Due to the fact that the particles vary greatly in dimensions and the surface dries faster than internal points, there is a gradual falling off of the shrinkage, while the moisture continues to decrease at about the same rate.

In the third stage the particles have all reached their minimum separation and the shrinkage entirely stops. During this third stage, however, moisture is still given off until finally all the free moisture has disappeared and there remains only the moisture of constitution in the particles themselves.

Bourry illustrates these three phases (Fig. 15) by tests on

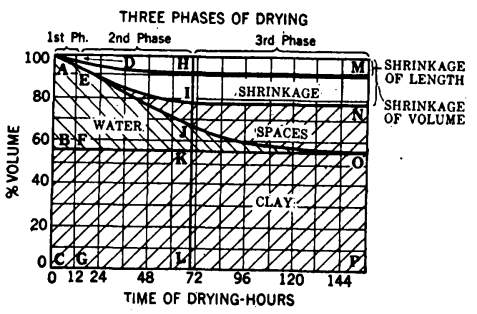

FIG. 15

Bourry's diagram of the relation of drying to volume, showing the percentage of clay, water, spaces, shrinkage of volume, and shrinkage of length.

a cylinder of clay having a length of five times the diameter. The diameter was 1.575 in. $(4 \mathrm{~cm}$.) and the length 7.874 in. $(20 \mathrm{~cm}$.). The volume of solid material in the beginning was 55 per cent and the volume of water 45 per cent. At the end of the first period, when the shrinkage and water decreased together, there was a reduction of 5 per cent in the volume which came from the loss of 5 per cent of the water, leaving 40 per cent. At this time the spaces between the particles were $O$; the lineal shrinkage was 3.7 per cent or $0.74 \mathrm{~cm}$.

At the end of the second stage of drying the volume of the clay was still 55 per cent, the volume of the clay and water was 67 per cent, and the volume of the water 12 per cent. The volume of the spaces between the particles was now 11 per cent. The total shrinkage was 22 per cent. The lineal shrinkage was 8 per cent.

At the end of the third period the percentage volume of water was 0 . The percentage volume of the spaces between the particles had increased to 23 per cent but the total shrinkage remained as at the end of the second period, namely 22 per cent. Also the percentage lineal shrinkage remained 8 per cent. All 
of these relations are better shown in the accompanying table, taken from Bourry's curves which are reproduced in Fig. 15.

\begin{tabular}{|c|c|c|c|}
\hline At the end of periods & 1 st & 2nd & 3 rd \\
\hline 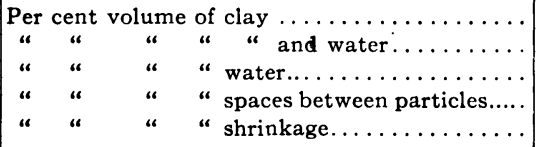 & $\begin{array}{c}55 \\
95 \\
40 \\
0 \\
5\end{array}$ & $\begin{array}{l}55 . \\
67 \\
12 \\
11 \\
22\end{array}$ & $\begin{array}{r}55 . \\
67 \\
0 \\
23 \\
22\end{array}$ \\
\hline $\begin{array}{ccc}\text { Per cent shrinkage in length. } \\
\mathrm{cm} \\
\mathrm{cm}\end{array}$ & $\begin{array}{c}3.7 \\
0.74 \\
0.06 \\
24 \text { mils } \\
0.4\end{array}$ & $\begin{array}{l}8 . \\
1.6 \mathrm{~cm} \\
0.027\end{array}$ & 8. \\
\hline
\end{tabular}

It is interesting to note that the lineal shrinkage decreased at the rate of 24 mils an hour or at the rate of 0.4 mil per minute. If we are to consider some scientific instrument for measuring the rate of shrinkage here is a variable factor which is available for use.

Another factor for use would be the variation in weight. For the sake of completeness Bourry's tabulated data of this test is given below.

\begin{tabular}{|c|c|c|c|c|c|c|c|c|c|c|}
\hline \multirow{2}{*}{\multicolumn{2}{|c|}{ Duration }} & \multicolumn{3}{|c|}{ Weight of } & \multirow{3}{*}{$\begin{array}{c}\text { Shrink- } \\
\text { age } \\
\text { lineal } \\
\text { Per cent }\end{array}$} & \multicolumn{4}{|c|}{ Volume of } & \multirow{3}{*}{$\begin{array}{c}\text { Per cent } \\
\text { total } \\
\text { volume }\end{array}$} \\
\hline & & \multirow{2}{*}{$\begin{array}{l}\text { Clay } \\
\text { per } \\
\text { cent }\end{array}$} & \multicolumn{2}{|c|}{ Water } & & \multirow{2}{*}{$\begin{array}{l}\text { Clay } \\
\text { per } \\
\text { cent }\end{array}$} & \multicolumn{2}{|c|}{ Water } & \multirow{2}{*}{$\begin{array}{l}\text { Spaces } \\
\text { per cent }\end{array}$} & \\
\hline Days & $\mathrm{Hr}$. & & $\begin{array}{c}\text { per } \\
\text { cent }\end{array}$ & $\begin{array}{l}\text { Per cent } \\
\text { change }\end{array}$ & & & $\begin{array}{l}\text { Per } \\
\text { cent }\end{array}$ & $\begin{array}{c}\text { Per } \\
\text { cent } \\
\text { change }\end{array}$ & & \\
\hline \multirow{4}{*}{1} & 2 & 75 & 25.0 & & 2.1 & 55.1 & 44.9 & & & 100.0 \\
\hline & 12 & 75 & 21.5 & 3.5 & 3.7 & 55.1 & 38.7 & 6.2 & 0.0 & 93.8 \\
\hline & 24 & 75 & 18.0 & 3.5 & 5.1 & 55.1 & 32.4 & 6.3 & 1.8 & 89.3 \\
\hline & 36 & 75 & 14.5 & 3.5 & 6.5 & 55.1 & 26.1 & 6.3 & 3.3 & 84.5 \\
\hline \multirow[t]{2}{*}{2} & 48 & 75 & 11.2 & 3.3 & 7.6 & 55.1 & 20.2 & 5.9 & 6.4 & 81.7 \\
\hline & 60 & 75 & 8.0 & 3.2 & 8.0 & 55.1 & 14.4 & 5.8 & 9.4 & 78.9 \\
\hline \multirow[t]{2}{*}{3} & 72 & 75 & 5.6 & 2.4 & 8.0 & 55.1 & 10.1 & 4.3 & 12.7 & 77.9 \\
\hline & 84 & 75 & 3.8 & 1.8 & 8.0 & 55.1 & 6.8 & 3.3 & 16.0 & 77.9 \\
\hline \multirow[t]{2}{*}{4} & 96 & 75 & 2.5 & 1.3 & 8.0 & 55.1 & 4.5 & 2.3 & 18.3 & 77.9 \\
\hline & 108 & 75 & 1.7 & 0.8 & 8.0 & 55.1 & 3.1 & 1.4 & 19.7 & 77.9 \\
\hline \multirow[t]{2}{*}{5} & 120 & 75 & 1.1 & 0.6 & 8.0 & 55.1 & 2.0 & 1.1 & 20.8 & 77.9 \\
\hline & 132 & 75 & 0.7 & 0.4 & 8.0 & 55.1 & 1.3 & 0.7 & 21.5 & 77.9 \\
\hline \multirow[t]{2}{*}{6} & 144 & 75 & 0.3 & 0.4 & 8.0 & 55.1 & 0.5 & 0.8 & 22.3 & 77.9 \\
\hline & 156 & 75 & 0.0 & 0.3 & 8.0 & 55.1 & 0.0 & 0.5 & 22.8 & 77.9 \\
\hline
\end{tabular}


As an additional factor the rate of drying has considerable to do with the value of the shrinkage. Two identical samples were dried at different rates. One sample was dried in one day and shrank 7.75 per cent. The other sample was dried slowly in 15 days and shrank 8.50 per cent, which is an increase of 10 per cent in the shrinkage.

The rate of drying is affected by the consistency, that is to say, by the percentage of moisture present. Bourry gives an illustration of samples of plastic porcelain in which the initial quantity of water was 10 per cent, 20 per cent and 30 per cent. The one with the highest percentage of water dried the fastest. The results are shown in the following table:

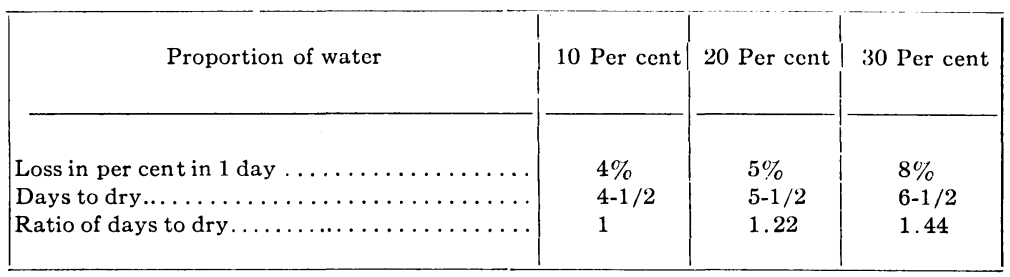

Since the rate of evaporation is affected by the amount of moisture present, if a tool used in forming the plastic porcelain squeezes out moisture locally mechanical strains will be introduced during drying which may cause laminations or cracks. This result may be due to the difference in content of moisture or it also may be due to a segregation of the plastic clay from the nonplastic powdered flint. The plastic clay will ooze through the solid flint and may produce locally a non-homogeneous condition. This non-homogeneous condition will affect not only the rate of drying and the plasticity but also the vitrification in the furnace when it is at its maximum temperature.

Bourry gives very little definite information regarding the content of moisture in the plaster of Paris molds. When the plaster of Paris molds are very dry the moisture is taken away from the surface of the porcelain, in contact with the mold so rapidly as to cause it to check. Where the "blank" is subsequently turned down on a lathe these surface cracks are turned off.

In every, case it must be understood that moisture cannot flow unless there is a different degree of moisture. Consequently the surface of the porcelain must always be drier than the interior and the problem is to keep this difference in degree of 
moisture to a value which will not cause cracks from unequal shrinkage. The movement of moisture from particle to particle corresponds to the transference of heat through an ordinary solid body, also to difference of potential in the electrical circuit. If projecting parts are used on the porcelain surface it is sometimes necessary to retard the evaporation from these localities where the area exposed, relative to the volume, is much greater than the same ratio for the main body of the drying porcelain.

\section{Flaws Developed During the Process of Drying and Dehydration in the Kiln}

Another critical stage apparently, in the manufacture of porcelain, occurs in the kiln at a temperature of 400 to $500 \mathrm{deg}$. cent. At this temperature the water of composition of the clay

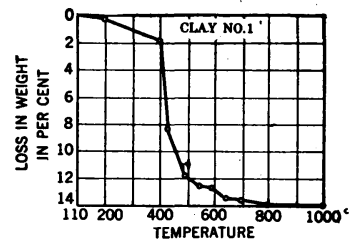

FIG. 16

The relation of loss of weight for different temperatures of firing on kaolin. (Messrs. G. H. Brown and E. T. Montgomery, Bulletin No. 21. By courtesy of Bureau of Standards.) was started, so that probably the free moisture had been all evaporated. From a temperature of 110 to $400 \mathrm{deg}$. the loss in weight was slightly less than two per cent but between 400 and $450 \mathrm{deg}$. the loss of weight was approximately 10 per cent and the total loss of weight up to $800 \mathrm{deg}$. was 14 per cent. From 800 to $1000 \mathrm{deg}$. no further decrease in weight took place. When we consider that the air-drying stage of a porcelain piece will usually require about three weeks and the decrease in moisture is less than occurs in the porcelain kiln it is seen that a possible damage might be done to the porcelain material during the early and apparently unimportant part of the firing. To remove from the body of a piece of porcelain 10 per cent of its weight in the form of moisture within a few hours would necessarily involve a rapid movement of moisture from particle to particle. The green porcelain is in a stage of drying in which the rate of drying may be high since there are only mall changes in volume 
taking place. The spaces between particles increase somewhat, that is to say, the porosity is greater at this stage. It is possible that a considerable expansion of the material may take place during this period and if the rise in temperature is too rapid the material will be puffed and warped by the sudden changes. If the air-dried porcelain is placed directly into a hot electric furnace it will be reduced to a powder.

There is a limit to the thickness of porcelain that can be successfully fired (in general about 1.5 in.) and it may be that one of the factors which gives this limitation is the method of firing universally employed, especially the rate of change of temperature in the neighborhood of $400 \mathrm{deg}$.

The effect of time on this dehydration of the kaolin is given

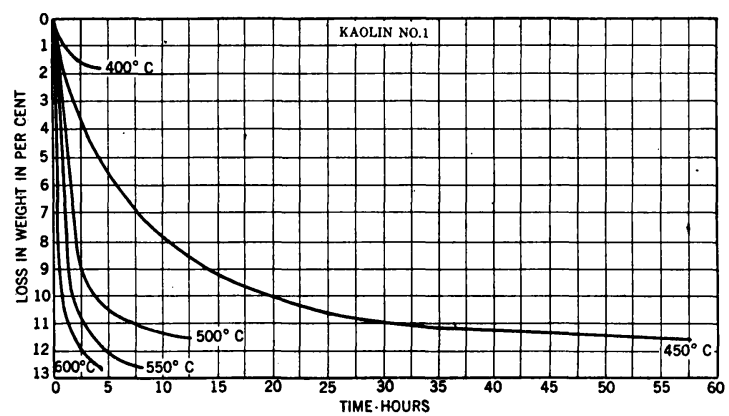

FIG. 17

The effect of duration of time on the dehydration of kaolin. (Bulletin No. 21. By courtesy of Bureau of Standards.)

in Fig. 17, taken from Bulletin 21. This curve shows that at a temperature of $450 \mathrm{deg}$., the most of the moisture will be thrown out in about 30 hours. At 500 deg. most of the moisture will be thrown out in five hours.

\section{Vitrification}

Another important stage of the formation of porcelain is the time of maximum temperature. The chemical dissolutions and combinations which take place in the semi-molten condition require considerably more time than when the materials are in a molten fluid condition. Consequently a temperature of 1310 deg. held for several hours may give complete vitrification, whereas a shorter time would leave the material under-vitrified. Briefly stated, the vitrification depends not only on the tem- 
perature but also on the duration of the high temperatures. The time of cooling is usually so slow that in general this is a stage of comparatively little danger, since the porcelain has already attained the characteristic of having a very small coefficient of expansion.

\section{Summary of the Important Points in the Manufac-} ture of Porcelain for Electrical Purposes

1. Composition (chemical and molecular).

2. Keeping the ingredients uniformly mixed.

3. Keeping the ingredients uniformly plastic.

4. Keeping the mass from unequal contractions in drying.

5. Keeping the mass from unequal contractions in firing.

6. Bringing the firing temperature to the proper range and holding it for the corresponding proper period of time to fill up the pores with vitrifying flux but not to cause a high degree of vitrification, forming a brittle, fragile mass.

\section{PART III. EXPERIENCES AND EXPERIMENTS IN TESTING PORCELAIN WITH THE HIGH FREQUENCY OSCILLATOR}

42. On the Subject of the Detection and Measurement of Superposed High Voltage on the Wave Trains of the Oscillator, the Superposed Voltages Being Due to the Reflection of the Local Oscillations of Creepage Sparks

It was noted in two different sets of tests that a type of porcelain bushing having an average puncture potential of $85 \mathrm{kv}$. under oil may apparently have a higher value of puncture voltage, as represented by the setting of the sphere gap, when a creepage spark is allowed to play over the surface of the oil between the two electrodes, the porcelain bushing in this case being near the surface of the oil so that its central metallic conductor is parallel to the oil surface and therefore in a position to encourage the formation of a creepage spark. Under these conditions of creepage spark the average puncture potential of a bushing of the same type was over $100 \mathrm{kv}$., an increase of 17 per cent.

There are so many variable factors in comparing these two conditions that it is difficult to draw directly definite conclusions as to the cause of the difference.

The following is a description of the two sets of tests, after which a discussion will be given of the various factors involved. 
A porcelain bushing, 13.5 in. long, and having an average thickness of 0.94 in. at the thinnest part of the corrugation, was supported horizontally on a metal rod and immersed in oil, Fig. 18. The metal rod was connected to the ground and a

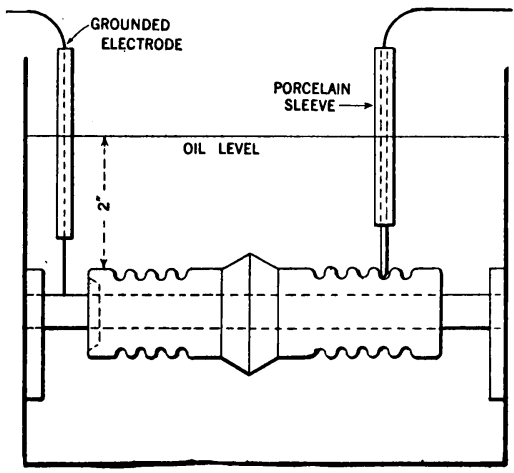

FIG. 18

One method of applying high-frequency potential to porcelain bushings under oil. The end of the electrode on the right was two in. wide and $\frac{1}{8}$ in. thick, rounded on the edges.

vertical electrode was placed in the groove of the corrugation. The width of the metal electrode was about one inch and its thickness about $3 / 16$ in. with the edges rounded off. Both these electrodes projected out of the oil at an average distance of 12 in. apart. Consequently, when the potential was applied

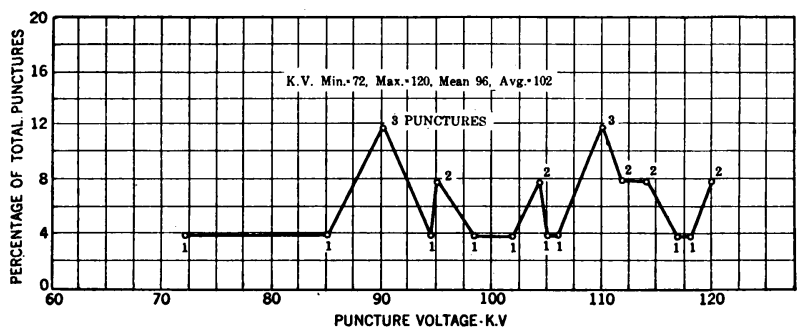

FIG. 19

Puncture voltage of porcelain bushing under oil. Representation of the percentage of punctures which took place at different impressed voltages as the voltage was gradually raised at the rate of about $5 \mathrm{kv}$, every 10 seconds. The numbers at the points represent the numbers of punctures at different spots of the same bushing.

above a certain voltage, sparks over the surface of the oil were produced between the two electrodes. The question arises, did the creepage sparks increase the gap setting of the spheres by superposing surges on the wave trains of the oscillator? We know from much experience in testing with 60 -cycle fre- 
quency that local sparks on an insulator or lightning arrester under test, will greatly increase the equivalent gap in parallel, although the voltage by ratio remains the same with or without the sparks.

There were 13 puncture tests made on one end of the bushing and 12 on the other, making a total of 25 punctures. The values of puncture potential, minimum, maximum, mean between the extremes, and average, are given in the table farther on.

It should be understood that these figures are not actual volt-

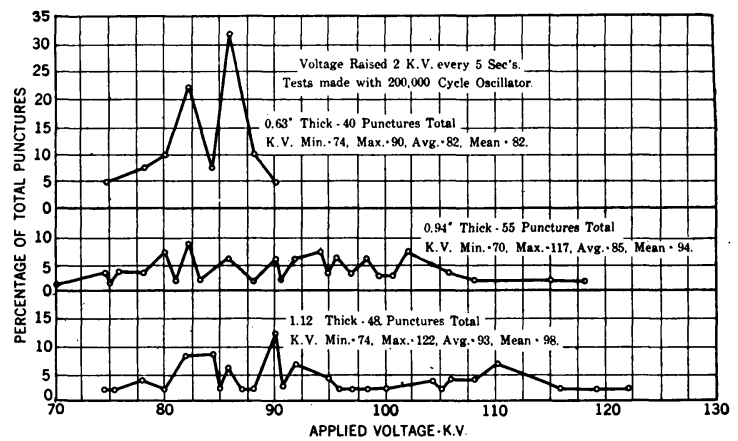

FIG. 20

Puncture of porcelain bushings under oil. Three different thicknesses are shown. Percentages of total punctures are plotted in relation to the kilovolts at puncture. Each curve represents punctures at different points on the same piece of porcelain.

ages but the voltages corresponding to the gap setting of the sphere gap as calibrated by tests with 60 cycles. The data of the tests are plotted in Fig. 19.

Another piece of porcelain of the same type, thickness, and manufacture was tested under identical conditions except that the creepage spark over the surface of the oil was entirely prevented. The plot of the data is shown in Fig. 20 of the second curve. There were 55 punctures total with an average puncture potential of $85 \mathrm{kv}$. as compared to $102 \mathrm{kv}$. in the previous test. This information is tabulated in the table below.

\begin{tabular}{|c|c|c|c|c|}
\hline & \multicolumn{3}{|c|}{$\begin{array}{c}\text { One bushing } \\
\text { tests allowing creepage spark }\end{array}$} & \multirow{2}{*}{$\begin{array}{l}\text { Another } \\
\text { bushing } \\
\text { tests with no } \\
\text { creepage } \\
\text { spark }\end{array}$} \\
\hline & 1 st end & 2nd end & Total & \\
\hline 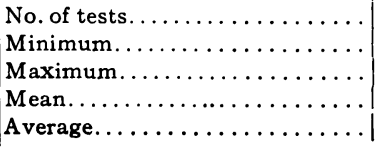 & $\begin{array}{r}13 \\
72 \\
114 \\
93 \\
96\end{array}$ & $\begin{array}{r}12 \\
90 \\
120 \\
105 \\
107\end{array}$ & $\begin{array}{r}25 \\
72 \\
120 \\
96 \\
102\end{array}$ & $\begin{array}{r}55 \\
70 \\
118 \\
94 \\
85\end{array}$ \\
\hline
\end{tabular}


To forestall questions which are bound to arise the following speculations are given: So far as the data here collected are concerned, the cause of this difference may be any one of several, alone or in combination. These possible causes will be enumerated: First, the porcelain bushings were fired at different times, and possibly at different temperatures, and the porcelain material may not have been identical in dielectric strength. (As a matter of fact tests will be given later to prove that the difference in porcelain constituted the entire difference in dielectric strength.)

Second. The creepage sparks over the oil make a demand for more energy from the oscillator and in so doing the regulation drops the voltage and therefore may require an increased length of the control gap.

Third. Momentarily there may be impressed on the circuit a high voltage corresponding to the unloaded condition of the transformer. This voltage may start a new creepage spark.

Fourth. The rapid extinction of the creepage sparks may reflect local oscillations of extremely high frequency back to the sphere gap and these local oscillations may cause the sphere gap, at a certain setting, to spark over more easily due either to a higher voltage or to a higher frequency, - - r both may exist at the same time.

Fifth. Again, another factor is involved in the relative dielectric spark lag of the 0.94 in. thickness of porcelain, and the long creepage spark over the surface of the oil. If the creepage spark takes place more quickly than the puncture of the porcelain the creepage spark by absorbing more energy and dropping the voltage may be an actual protective gap to the porcelain.

Sixth. There is also a factor which enters into this problem in the matter of time of application of voltage on the surface of the porcelain. The electrode employed has comparatively thin edges and therefore its potential gradient will be high at the surface of the porcelain. This high potential gradient when the voltage is carried up to a value approaching the puncture potential, will begin to damage the porcelain locally at the electrode. Failure of the porcelain should therefore be a gradual growth depending upon the time of application.

If the user of the oscillator had to take into account all these complex factors it would require a rare technical skill. It will be the object of the studies which immediately and later follow, to show that complications of superposed oscillations, frequency, 
and so forth are usually negligible factors in testing insulators with the oscillator. The problem is thereby stripped of most of its complications, leaving a simple condition which takes care of itself automatically in the practical procedure of testing.

43. Tests to Determine whether Corona Streamers and Corona Sparks Produce Local Oscillations in the Circuit which Affect the Sphere Gap Setting

In the previous tests of porcelain bushings the electrodes were so arranged that a spark could take place over the surface of the oil just above the bushing. With this arrangement it was possible to limit the stresses on the bushing to a local point where the upper electrode touched it, yet at the same time get a creepage spark over the surface of the oil. Ordinarily when tested in air the creepage spark over the surface of the porcelain is liable to find some weaker spot than the one where the electrode rests and thereby cause a discontinuation of the experiments by puncture.

In order to exaggerate the effects of creepage sparks, a pane of glass $\frac{1}{8}$ in. thick was used as dielectric. The electrodes consist of two iron rods $\frac{1}{2}$ in. in diameter with rounded ends. These electrodes were placed in the same axial line on opposite sides of the glass.

\section{First Set of Tests on Glass}

In the first set of tests the control gap and equivalent spark gap were increased at the same time. As the impressed voltage was increased the corona streamers, mostly blue but sometimes slightly white, increased in area over the surface of the glass. At the maximum voltage obtainable, namely $45 \mathrm{kv}$. by spark gap with a setting of $11.1 \mathrm{kv}$. on the control gap, the radius of the corona was $5 \frac{3}{4}$ in., giving a total area on each side of the glass plate of 104 square inches. The following series of readings was taken:

\begin{tabular}{|c|c|}
\hline Control Gap & Spark Gap \\
\hline ' & \\
\hline $\begin{array}{r}1.8 \mathrm{kv} \\
3.0 ، \\
4.6 “ \\
6.7 ، \\
11.0 \text { “ }\end{array}$ & $\begin{array}{l}32 \mathrm{kv} . \\
34 \text { “ } \\
36 \\
38 \text { “ } \\
40\end{array}$ \\
\hline
\end{tabular}


As an explanation of why the voltage generated by the oscillator is apparently so very limited we must look to two different causes. First, the corona is equivalent to an increase in capacitance. Second, the corona absorbs energy. Either of these causes will limit the potential of the oscillator by ovcr-loading it.

In order to determine the effect of capacitance, tinfoil plates, 7 by 9 in., ( 63 sq. in.) were used as electrodes. As a result the maximum voltage obtained was reduced from $45 \mathrm{kv}$. as given in the previous test, to $28 \mathrm{kv}$. Even at $28 \mathrm{kv}$. there was a corona of $1 \frac{1}{2}$ in. visible in daylight surrounding the tinfoil plates. This made a total area covered by plate and corona of 10 by 12 in. (120 sq. in.). During this test the control gap was set on 11.5 $\mathrm{kv}$. With the electrodes alone the area was 104 sq. in. which was increased to 120 sq. in. with the plate and corona together. This increase of 16 per cent in area reduced the voltage by 37 per cent. The area of corona around the metal plates was 57 sq. in. which is a little less than half of the corona area in the previous case. It would appear from these figures that the capacitance was a large factor in reducing the voltage at the terminals of the oscillation transformer.

Capacitance of glass plate $\frac{1}{8}$ in. $(0.322 \mathrm{~cm}$.) thick and an area of $104 \mathrm{sq}$. in. ( $670 \mathrm{sq} . \mathrm{cm}$.) is 1.1 milli-microfarads $\left(10^{-9}\right.$ farads).

At 300,000 cycles and $45 \mathrm{kv}$. this capacitance of $1.1 \times 10^{-9}$ farad gives a momentary load of about 29 amperes or $1170 \mathrm{kv}$-a.

This eapacitance of 1.1 milli-microfarads is equivalent to the capacitance of thirty suspension type insulators in parallel, which is three to six times full load for this oscillator.

\section{Equivalent Spark Gap of Corona on a Glass Plate}

The equivalent spark gap of corona on glass plates is dependent upon the voltage applied. Two tests of a slightly different nature follow. In the first one, the spark gap was set permanently on $37 \mathrm{kv}$. and the control gap was gradually increased. With the control-gap setting of 3.2 , a spark was formed around the edge of the plate which was $4 \frac{1}{2}$ in. away from the electrode, making a total length of spark of 9 in. No discharges took place over the spark gap for this low setting of the control gap.

At a setting of $4 \mathrm{kv}$. of the control gap there was one discharge over the spark gap in seven total.

At five kv. setting of the control gap there were four sparks over the spark gap to ten total. 
At six kv. setting of the control gap there was about equality between the spark gap and the spark around the glass plate, that is to say, five out of ten total.

At seven kv. setting of the control gap the sparks over the spark gap increased to seven in ten impulses.

At eight $\mathrm{kv}$. setting the sparks over the spark gap increased to eight in ten impulses.

At $8.5 \mathrm{kv}$. setting of the control gap there were nine discharges over the spark gap out of a total of ten impulses.

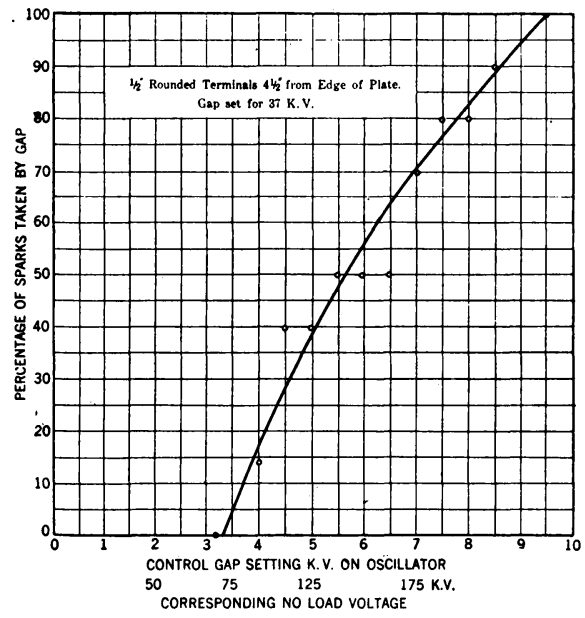

FIG. 21

Arc-over tests on a glass plate $\frac{1}{8}$ in. thick and with the electrodes $4 \frac{1}{2}$ in. from the edge of the plate. Electrodes were placed in the same axial line perpendicular to the plate, consisting of in. rods with the ends rounded. The gap was set constantly on $37 \mathrm{kv}$. and the control gap was gradually increased. For low values of the control gap $3.2 \mathrm{kv}$. all the discharges took place over the surface of the glass and a creepage spark of total length of 9 in.

At nine kv. setting of the control gap there were 19 discharges over the spark gap out of 20 total.

At $9.5 \mathrm{kv}$. setting of the control gap there were 40 discharges of the spark gap out of a total of 40 , but at a setting of ten $\mathrm{kv}$. on the control gap one discharge took place over the glass plate, making a record of 39 over the spark gap to 40 total.

At a control gap setting of $10.5 \mathrm{kv}$. there were 100 successive discharges over the spark gap out of a total of 100 impulses, there being very slight tendency to spark on the glass plates.

In this set of tests it is seen that the equivalent spark gap of electrodes separated by a thin glass plate depends upon the value of the applied potential the same as has been shown in 
tests on lightning arresters using Leyden jars charged from the static machine.

The change in the equivalent spark gap is shown diagrammatically in Fig. 21.

46. The Equivalent Spark Gap with the Control Gap REMAining Constant

In the next set of tests the control gap was set on $3.5 \mathrm{kv}$. which was just sufficient to cause $4 \frac{1}{2}$ in. radius of corona, and a spark around the edge of the glass plate. It was necessary to reduce the spark gap from $37 \mathrm{kv}$. setting to $32 \mathrm{kv}$. setting in order to take the spark away from the glass plate. It should be recalled that at high control-gap setting the spark gap set even on $37 \mathrm{kv}$. took all the discharge away from the glass plates.

By increasing the control gap setting to four $\mathrm{kv}$. and with a setting of $32 \mathrm{kv}$. on the spark gap, it was possible to take away the discharge from the glass plates and keep it in the spark gap. When the spark gap was increased two kv. to $34 \mathrm{kv}$. there were 32 discharges over the spark gap out of a total of 40 , leaving eight discharges over the glass plate.

With the control gap setting of $10.5 \mathrm{kv}$. it was necessary to elongate the spark gap to $44 \mathrm{kv}$. before the discharges would all take place over the glass plate.

In none of these tests do we find the solution of the problem of the effect of the oscillation set up by the corona streamers and corona sparks. Therefore the next set of tests is planned to throw some light on this subject.

\section{The Puncture Voltage of a Glass Plate with a Drop of Oil Around the Electrodes}

The same electrodes were used and a glass plate lying horizontally had a few drops of oil placed around the upper electrode. The main gap of the oscillator was then closed momentarily a number of times with control gaps ranging from one kv. up to $2.5 \mathrm{kv}$. The spark gap voltages corresponding were from 32 kv. up to $40 \mathrm{kv}$, After the eighth brief application of potential with a setting of $2.5 \mathrm{kv}$. on the control gap and $40 \mathrm{kv}$. on the spark gap the glass was punctured. This experience gives a very definite clue to the immunity of puncture in the previous test. It should be recalled that the control gap setting was increased to $11.1 \mathrm{kv}$. and the spark gap to $45 \mathrm{kv}$. without caus- 
ing a puncture of the glass. We now applied less voltage and very quickly got a puncture. The distance of the electrode from the edge of the glass in this last case was only $1.3 \mathrm{in.}$ and occasionally there would be sparks break through or over the surface film of oil and spark around this short width of glass.

The obvious explanation of this phenomenon of puncture of glass at lower voltage than it had previously withstood is in the difference in concentration of the electrostatic field. Without the film of oil the voltage gradient at the electrode can rise only to a value which will start the corona discharge in air and any further increase in the voltage simply increases the area covered by the corona which, in effect, increases the area of the plate and gives a better distribution of the electric field over the plate. On the other hand, when the oil is used, the corona streamers are to a very great extent restricted and the potential is concentrated locally and causes a disruptive spark to puncture the glass.

While the variations in the equivalent spark gap involved a complicated study of dielectric spark lags the actual use of the oscillator to measure these different conditions is very simpie. We must assume in each case that even if the spark gap does not measure the actual voltage it does measure always the tendency to spark which is the condition in the circuit against which it is desirable to protect. In testing porcelain bushings in air the same effect will take place as shown in the tests on glass in that the corona at the edges of the electrodes will decrease the effect of the sharp edges of the electrodes. In testing thin pieces of pr rcelain in air many new points of the porcelain are reached by the spreading of the corona streamers and there will be added the additional factor of puncture through local weaknesses in the porcelain. The porcelain is not nearly as homogeneous as glass. The wave trains generated are of very high frequency and the superimposed oscillations from local sparks, while higher in frequency, are, comparatively speaking, not much higher. As a result the spark gap is not affected very much. In other words, the change of frequency and wave front from 60 -cycles to say a million cycles is enormous as compared to the change of frequency and wave front from the oscillator to that of the local oscillations. The first ratio is of the order of 17,000 and the second of the the order of 3 . Herein lies the simplicity of testing with the oscillator. 
In testing porcelain under oil one must take into account the maximum voltage gradier $t$ which can be applied at the contact point between the electrode and surface of the porcelain without damaging the porcelain. This value of voltage gradient is readily determined experimentally for any particular shape of electrode that it is desired to use. Such tests will be given further on.

48. Further Studies of Puncture Potential of Porcelain Under Oil by the Use of the Oscillator

Three thicknesses, namely 0.63 in., 0.94 in., and 1.12 in., were tested and recorded. The test pieces were corrugated porcelain bushings of the gereral form shown in Fig. 18. In Fig. 20 three curves are shown of tests on the three thicknesses. The three pieces of porcelain were each punctured a number of times. By conducting many tests on one piece of porcelain it is thus possible to keep the factor of quality of the porcelain constant. The three curves are entirely irdeperdent. The method of test was to gradually raise the potential two kv. every five seccnds until puncture occurred. In plottirg this data the kilovolts at puncture are taken as the abcissas and the percentage of the total number of punctures at the different voltages as the ordinates. The upper curve is the result of 40 punctures total, all on one test piece. The minimum puncture potential was $74 \mathrm{kv}$. There ware two punctures at this voltage, which is 5 per cent of 40 total punctures. Percentage is used instead of the actual number of punctures in these curves so that comparisons can be made between the three different thicknesses tested. There were only two places tested that withstood $90 \mathrm{kv}$., the maximum value. This is also shown as 5 per cent on the upper curve. Attention is directed to the peculiar low point at $84 \mathrm{kv}$., as it will be shown in a different way in another diagram later. It may or may not have any special significance. Attention should also be directed to the small range of puncture potential for this thickness of 0.63 in. Most of the punctures occurred between 80 and $88 \mathrm{kv}$. These general relations may be interpreted from a tabulation of the maximum, minimum, average, and mean between the extreme values as printed on the curves. The ratio of the minimum to the maximum is 82 per cent and the mean and average values are identical, showing general symmetry in the results.

The second curve (0.94 in. thick) is the result of a total of 55 . 
punctures taken on one bushing. This greater thickness shows a wide range of puncture voltage. The minimum puncture voltage of $70 \mathrm{kv}$. was even less than the thinner test piece. The maximum puncture voltage was $118 \mathrm{kv}$. but there was only one spot that withstood this potential. For this greater thickness of porcelain there is no definite puncture voltage as in the previous case. The ratio of the minimum to the maximum is 60 per cent which is 22 per cent below the range of the thinner porcelain just given above.

In the third curve the thickness was 1.12 in., and a total of 48 punctures was made on the porcelain piece. Here again the puncture voltage is spread over a wide range with no definite point of failure. Apparently in both of these thicker pieces the conditions of manufacture or test of the porcelain were such as to give a wide range of dielectric strength. The ratio of the minimum spark potential in this case was also 60 per cent. In the early part of the work it was endeavored to get as many punctures as possible on one sample. In so doing it was found that the cracks from one puncture would occasionally carry into the spot where the successive test potential was applied ard this spot would thereby be weakened. As soon as this fact was established greater distances were made between puncture points. To further insure that the cracks did not carry from one puncture hole to the next, further precautions were taken. The punctures were filled with red stain and then thoroughly dried, the porcelains were then broken into pieces and where the red stain showed that a crack had carried from one punctured point to another the second reading was thrown out.

49. A Replot of the Data of Fig. 20 to Show Tentatively Possible Natural Gradations of Flaws

In Fig. 20 the percentage of the total number of punctures at each value of kilovoltage applied was given. In Fig. 22 the values of punctures are summed up from the lowest voltage to the highest voltage. Both curves, 1 and 2, show a peculiar shoulder at $82 \mathrm{kv}$. All the curves show a bend at the highest values. Tentatively, we may interpret these curves as follows: It is conceivable that there is a certain class of flaws which are devloped between $70 \mathrm{kv}$. and $82 \mathrm{kv}$. Above this value we get into the condition of the normal strength of the porcelain which requires a considerable increase above $82 \mathrm{kv}$. before the number of failures again increases rapidly. In the case of curve 1 it 
required $85 \mathrm{kv}$. to increase the percentage suddenly from 53 to 85 . In curve 2 the range was wider, being between $90 \mathrm{kv}$. and $100 \mathrm{kv}$. In the third grade of the dielectric strength given by the porcelain there are those local spots which approach perfection in the homogeneity of the porcelain material. Therefore the high-voltage strains which are at the limit of dielectric strength do not develop into a puncture so easily. As already stated, this analysis is only tentative, and even if it is true for this particular grade of porcelain it may not apply in the same way to a different mixture of material. We have found, how-

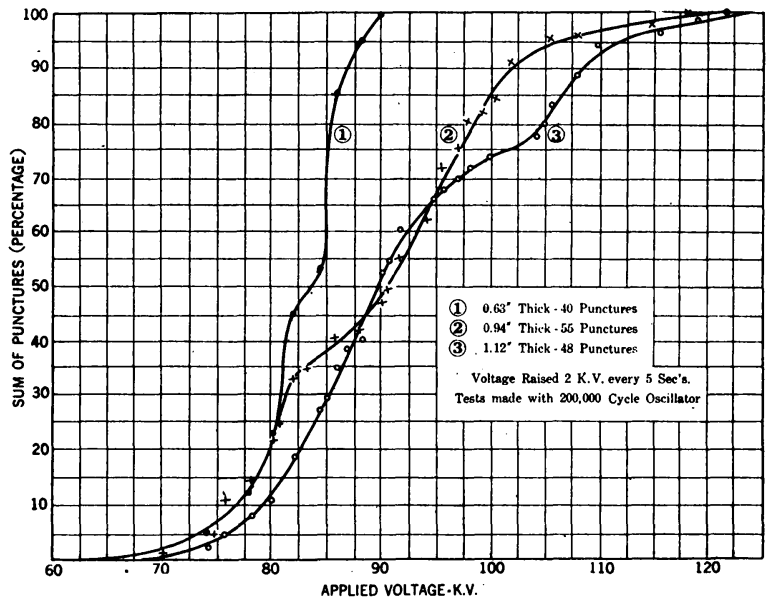

FIG. 22

A replot of the puncture tests of Fig. 20. The kilovolts of puncture versus the sum of punctures. The shoulders on the curves may represent a different grade or kind of flaw in the porcelain.

ever, that there have been in nearly every case fairly definite degrees of flaws which can be developed in rather definite ranges of potential. To illustrate this idea, the grades might be divided as follows: First, accidental cracks or lamination which are at more or less of an angle to the surface of the porcelain and which therefore decrease the puncture length through the porcelain. In the second grade would be those flaws of the nature of "blebs" or closed bubbles also open pores. In the third grade there exists the highest degree of homogeneity with very slight differences in dielectric strength from particle to particle as we pass from surface to surface. 
50. Tests with the Electrode placed Successively in the Valley of every Adjacent Corrugation in the Surface of the Bushing. The Results show the Internal MeChanical Strains due to Shrinkage

In the records of the tests shown in Fig. 19 the upper electrode was always moved a distance of two corrugations away from the previous test. In the earlier tests the electrode was moved into the adjacent corrugation. In so doing some interesting conditions relative to internal strains were disclosed. Fig. 23 shows one of several punctures which took place in the porcelain. It will be noted that there are two streaks which are only 0.25 in. apart but are 0.81 in. long. If the porcelain had been uniform there would have been a straight puncture through the porcelain perpendicular to the surface $(0.62$ in, $)$. The fact that

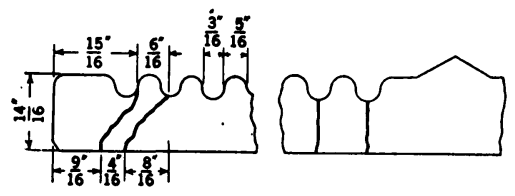

FIG. 23

Parallel puncture streaks close together as compared to the length of the streak. This phenomenon shows latent weakness in the porcelain at the end of the bushing, which seems to be due to the process of air drying.

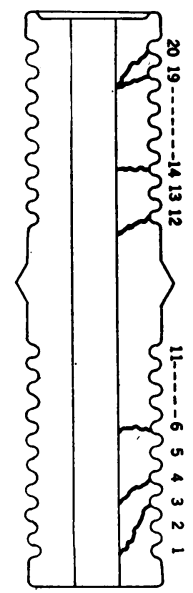

FIG. 24

A number of puncture streaks are shown at different lengths of the bushing similar to those of Fig. 23. It should be noted that all the puncture streaks at the ends and at the middle are in a downward direction, which seems to indicate the effects of air drying in causing latent cleavage surfaces in the porcelain.

there are two punctures about 0.8 in. long side by side following parallel paths separated by only one-quarter inch indicates that there were mechanical strains in the porcelain, placed there during the manufacture, which caused more or less of a cleavage or a line of weakness. This porcelain was jiggered into the form of a long, smooth tube while it was in a plastic condition. After partial drying sufficient to give it enough tenacity to hold together, it was placed on a lathe and the grooves or corrugations turned into the surface of the "blank." The material was then allowed to complete its drying. Probably during this second process of drying these laminal strains were introduced. There is every reason to believe that the 
lamination is not due to a layer of flint, because in the working of the soft clay there is no opportunity to systematically cause layers in the direction shown by the direction of the punctures.

In Fig. 24 are shown the paths of puncture of another porcelain bushing at several points along its length which would tend still further to confirm the belief that the cracks were due to airdrying rather than to lack of homogeneity of mixture or shrinkage in firing. The lines drawn from the grooves to the inside surface of the porcelain bushing show that at the ends and at the middle the direction of the puncture is at an angle from the radial direction and all in a parallel direction. Punctures at other points than at the ends or the middle are radial punc. tures. The possible explanation is as follows: This porcelain bushing was stood on one end to dry. It was therefore restricted in its radiation of moisture from the surface at the base and was given extra freedom of evaporation at the upper part where the central hole was open to a slight movement of the air in the neighborhood. About half-way along the bushing the thick. ness was increased to be used as a support and at this point also there would be a difference in drying at different depths. The under side of this shoulder would naturally get more evaporation than the upper side. Since the thickness was greater a greater amount of moisture had to be extracted, requiring a longer time for different depths. If these angular weak spots had been produced by a variation in the mixture they would have been more or less uniform in the bushing from end to end. If the angular weaknesses were due to firing in the kiln there would seem to be no reason for the peculiar distribution at the top and bottom, although naturally the thicker part of the bushing at the midway point would come in for inequalities of contraction. As a matter of observation, two small surface cracks were noted on the inside of the bushing at the thickest point but these cracks did not show sufficient weakness to divert the puncture discharge from its path, which, by the way, ended about $\frac{1}{4}$ in. from the surface crack.

\section{Faults in the Skirts of Suspension Insulators}

When the upper side of a skirt of an insulator is covered by tinfoil and the insulator inverted in a bath of oil, localized potentials can be applied by means of a small electrode resting in one of the corrugations or valleys between adjacent petticoats. In a number of test samples'a very uniform homogeneous porce- 
lain material was found. This was indicated by punctures directly between electrodes from surface to surface of the porcelain. Occasionally, however, conditions of internal mechanical strains were revealed by the fact that the puncture took place at an angle to a perpendicular line between surfaces and sometimes traversed a distance nearly twice as great as the thickness of the porcelain. The direction of the puncture was indicated subsequently when the porcelain was broken up with a hammer or by squeezing it in a vise. Fig. 25 shows a sketch of two different types of punctures that were found.

In a number of punctures which occurred in the head of pintype insulators a careful examination was made by staining and breaking up the porcelain by hammer blows. A characteristic puncture streak is shown in Fig. 26. These samples were shown to a porcelain manufacturer who immediately set the cause of

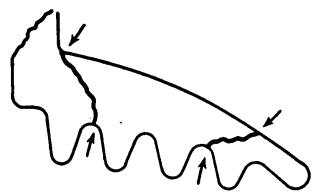

FIG. 25

Directions of puncture in a skirt of a porcelain insulator where the discharge takes a path much longer than the shortest distance between surfaces. This indicates a weakness in dielectric strength due to shrinkage strains.

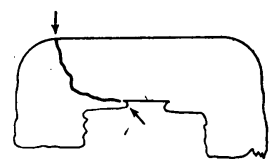

FIG. 26

Direction of puncture in the head of a pin-type insulator, showing a line of weakness due primarily probably to an improper manipulation of a forming tool, while the porcelain was in a plastic condition. All paths of puncture which do not take the shortest distance indicate a line of weakness in the porcelain.

the trouble to an improper use of the tool used in forming the thread on the inner surface of the porcelain. With the information already given, one may attribute the fault to insufficient plasticity, which may have been due to lack of water, lack of enough ball clay, or too large particles of flint. It is easy to conceive of the more plastic clay being squeezed out from under the tool, leaving the material directly under the tool of a different consistency from the rest of the body of the porcelain. From this difference in body, weaknesses may be caused, either in the rate of drying or in the vitrification due to the improper proportioning of the ingredients in this locality. In one case there was a perceptible surface crack in the porcelain which was the beginning of a puncture streak. In this case one may tentatively infer that the damage was initially done in drying and might have been found by the application of oil to the green porcelain. 
In general one may conclude that porcelain which does not puncture through the shortest distance is non-homogeneous.

\section{The Growth of Corona on Insulators}

The growth of corona around the electrodes and on different parts of the insulators has been successfully used as a basis of design. The oscillator with its high frequency is well adapted to bring out the characteristics of design by this method. Some tests are given in the following table to illustrate the characteristics as disclosed by the oscillator. The tests were invariably made in the dark to be able to note the first visible formation of corona.

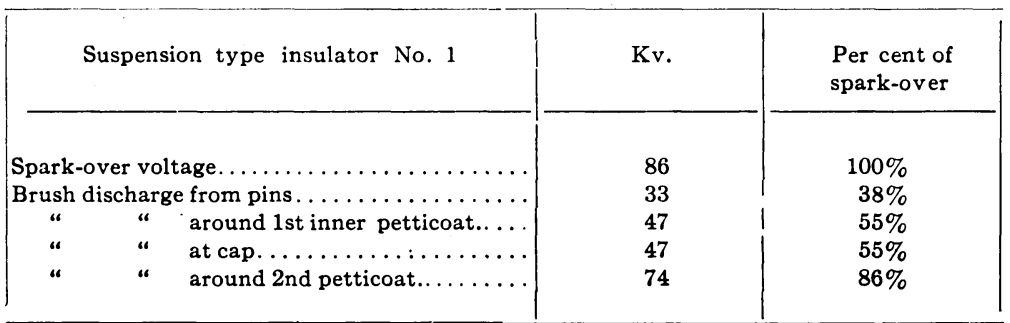

It was found impossible to brush discharge over the third petticoat without a spark-over on the insulator.

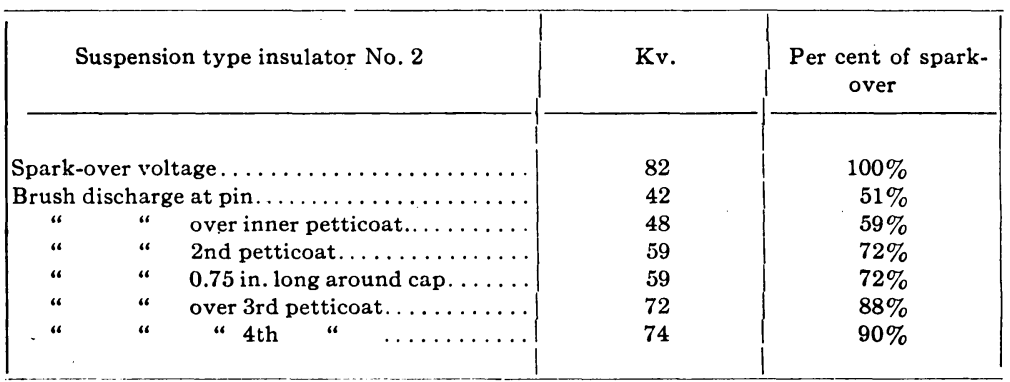

In studying the growth of corona on the pin-type insulators, eight different samples were used. In the points of Fig. 27 the appearance of the corona in per cent of the spark-over voltage is plotted as ordinates and the kilovolts of spark-over voltage as abcissas, the points corresponding to the initial formation of corona which invariably took place around the pin. A considerable variation in the distribution of polential is evident from the wide variation between the limiting curves as shown in Fig. 25. The variation is from 30 per cent for ihe high-voltage insulators, to 76 per cen; for one of the best conditions of the lower-voltage insulators. Naturally the higher the spark-over voltage of the 
insulator the lower the percentage, because the corona depends upon the potential gradient. The potential gradient which produces corona on the pin does not differ very widely for the different types of pins and insulators.

\section{Significance of these Tests}

The significance which may be drawn from tests of corona are too complex to be considered in a paragraph. They are valuable to the designer but several points of design must be taken into account in each particular insulator. From some

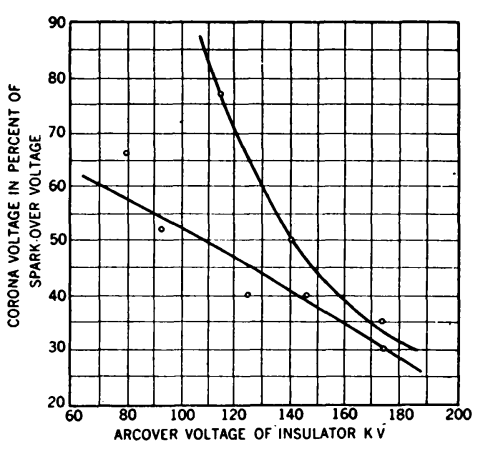

FIG. 27

The first appearance of corona on pintype insulators using the oscillator as a source of power. Arc-over voltage of the insulator versus the percentage of arc-over voltage at which the first corona appears on the pin. The two curves show the wide range of variation which can be found in insulators on the market at the present time. points of view the ideal design of an insulator would be one producing no corona until the arcover voltage of the insulator was reached. From a practical point of view the laboratory test, unless made under the same conditions as found in the operation of the insulator, does not necessarily give the best design. For example, if an insulator is to be designed for a very dusty country or where soot and smoke will be deposited on the surface of the porcelain the conditions call for extra long surfaces for creepage. If such an insulator in a clean condition is tested in the laboratory for the appearance of corona, the corona will appear at a comparatively small fraction of the arc-over voltage. Yet if this insulator is thoroughly coated with a semi-conductor, as would occur in practise, it is quite probable that the apparently faulty design would be fár better than one with shorter skirts which in the laboratory test in a clean condition gives a higher percentage of voltage for the appearance of corona. In brief, one must take into account the use of the insulator and reproduce the operating conditions, as far as possible.

\section{Percentage of Failure as a Criterion of Rejection OF INSULATORS}

This would seem to be a very good rule but it may not be desirable to apply it blindly. The full significance of the tests 
is not yet evident. In considering the failure of insulators we must take into account the nature of the weakness. Weakness from under-firing porcelain may be more serious than weakness from over-firing. Under-fired porcelain is liable to be uniformly weak all the way through. Over-fired porcelain is liable to be weak in local spots such as cracks.

To illustrate this point examples are taken from a number of endurance runs that were made on insulators which by examination showed thorough vitrification and a tendency to the side of over-firing.

Type X. Of three insulators, one failed in one min. (33 per cent) two were not punctured in 1 hour of test.

Type Y. Of eight insulators, three failed in one min. (37 per cent) five were not punctured in 1 hour of test.

Type $Z$. Of three insulators, none failed in one min. ( 0 per cent) all withstood 1 hour.

Type D. Of three insulators, none failed in one min. ( 0 per cent) all withstood 1 hour.

The experience of the Types $\mathrm{X}$ and $\mathrm{Y}$ in the above tabulation, although limited, would indicate that some caution should be taken in the rejection of insulators. It may even be that a high percentage of loss may be a good criterion of choice under certain conditions of over-firing. A hypothetical case will be given for illustration: The temperatures in the different parts of a kiln and the time of application of the vitrifying temperature must necessarily vary. The intensely hot flames enter at certain points and the partially cooled flames leave at other points. Both of these places cannot be at exactly the same temperature. Even assuming a final negligible difference of temperature, the porcelain nearest the entering flame must be at a vitrifying temperature somewhat longer than the porcelain near the flues. The cracks in such over-fired porcelain produce dielectric weakness and the insulators are therefore easily detected when tested, and rejected.

We may deduce that a considerable percentage of over-fired porcelain may indicate that the rest of the kiln-ful is perfectly fired. On the other hand, a temperature that will just properly vitrify the hottest spots in the furnace may leave the larger percentage of insulators at a low grade of vitrification. Their dielectric strength may be barely sufficient to pass the usual test and therefore from a standpoint of dielectric strength they are inferior insulators to the hypothetical lot that was rejected 
on the basis of 3 per cent failure. It is intended here only to point out that more must be known of the intimate history of a porcelain insulator to judge its worth on the basis of a percentage rejection. Intrinsic mechanical strains, layers of flint, relative conditions and rapidity of drying of a batch of insulators, rate of firing, etc. must be known to give proper weight to the basis of rejection by percentage failure.

\section{Welding up the Puncture Holes in Porcelain by} the Application of High-Frequency Wave Trains

Under certain conditions of puncture it has been found practicable to repeatedly puncture and weld up the puncture holes in porcelain. This may not be entirely unknown in tests with 60 cycles although no such experience has been had by the author. There seem to be certain requirements to successfully weld up the holes without failure. The best results were obtained by Mr. Cermak in the tests of large porcelain cups which were made up of several different kinds of clay but all fired at the same time. These cups were partially filled with water which acted as one electrode and the other electrode was a wire wrapped around the outside. The punctures noted never took place directly under the wire and therefore no copper vapor was carried directly into the puncture hole. Since the other electrode was water, no metallic vapor could be obtained from this source. The time of application was varied considerably but three seconds on an average would give good results. The punctured spots in this porcelain appeared as a small bead of clear glass which actually had greater dielectric strength than the porcelain elsewhere; as no welded punctures were repunctured by a second application of potential. No doubt the content of feldspar in the porcelain will have an effect on ease of formation of glass or glaze in the punctured holes.

In other porcelain in which different ingredients were used and which seemed to be less homogeneous, cracks were caused. which of course could not be welded up by the high frequency arc. It is very probable that welding up of punctured holes by 60 -cycle tests is not common because the punctures are more liable to take place directly between the electrodes and therefore become filled with metallic vapor which leaves the melted porcelain in the path of the arc of weak dielectric strength. The use of the high frequency produces widely extended corona and thereby picks out flaws or weaknesses which are frequently some distance 
away from the electrodes and thereby avoids the deposit of metallic vapor in the punctured holes. When punctures are made under oil there have been no cases of welding up of the punctured holes due probably to the carbonization of the oil which is always found in the punctured streak.

55. Comparative Puncture Voltages of Porcelain to Glass. Porcelain Pieces of Different Thicknesses Were used but the Glass was Built up of Panes Piled One on Top of the Other

The results of these tests are shown in Fig. 28. Curve 1 was made taking puncture potential on glass of increasing thicknesses.

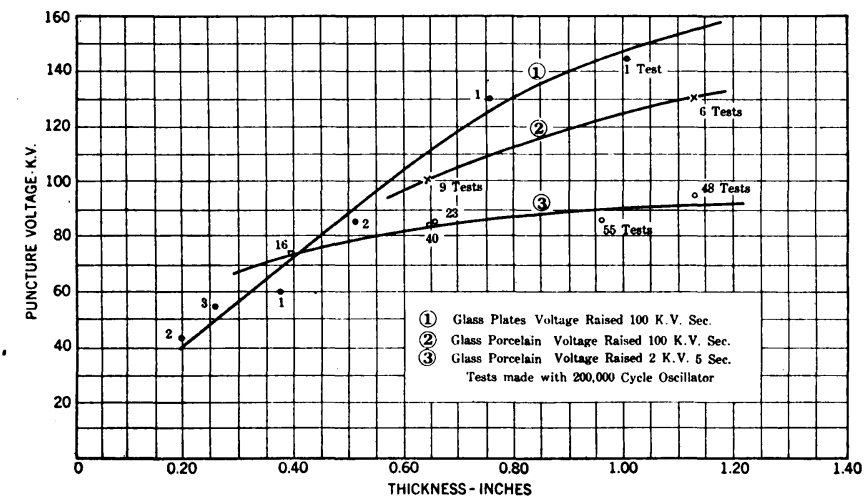

FIG. 28

Comparative puncture tests of glass and porcelain. The connections were made as shown in Fig. 18. Relations are shown of thickness versus puncture voltage. In Curve 1, the thickness of glass was obtained by building up sheets of glass with a thin film of oil between. The voltage was raised at the rate of $100 \mathrm{kv}$. per second. The small numbers placed near the points represent the total number of tests made at the different thicknesses.

Curve 2, made from porcelain of different thicknesses with the voltage raised at $100 \mathrm{kv}$. per second, the same as in the glass.

Curve 3 is also from in the giass. increase in the voltage. It was increased at the rate of $2 \mathrm{kv}$. every five seconds or $1 / 5 \mathrm{kv}$. per second. Curve 3 will be seen to give the results of an average of many tests on bushings with corrugated surfaces.

Each individual thickness of the glass was $1 / 16$ in. and each piece of glass was immersed in oil before it was pressed against the adjacent sheet which of course left a thin film of oil between the plates of glass. The curve shows an almost direct increase of puncture potential with an increase of thickness.

Curve 2 has only two points-one the average of six tests at $1.2 \mathrm{in.} \mathrm{thickness} \mathrm{and} \mathrm{the} \mathrm{other} \mathrm{an} \mathrm{average} \mathrm{of} \mathrm{nine} \mathrm{tests} \mathrm{at} 0.62 \mathrm{in.}$ thick. The tests which gave the data for curve 2 had a more rapid rise in the testing potential than the tests of curve 3 . The porcelain also differed. The higher puncture potential may be 
credited to both of these conditions, namely different porcelain and more rapid increase of testing potential.

The points of curve 3 are the average of 182 tests total and therefore may be considered a fair average of the porcelain which we had at hand. An important result shown by this curve is that increase in thickness of porcelain from 0.4 in. to three times as much or 1.2 in. gives an increase in puncture potential from only $74 \mathrm{kv}$. to $91 \mathrm{kv}$. which is 13 per cent. Three hundred per cent increase in thickness gives 13 per cent increase in puncture potential. Although this general condition of increasing the thickness without increasing the puncture potential is known, the small percentage of gain from an increase in thickness may be new to many.

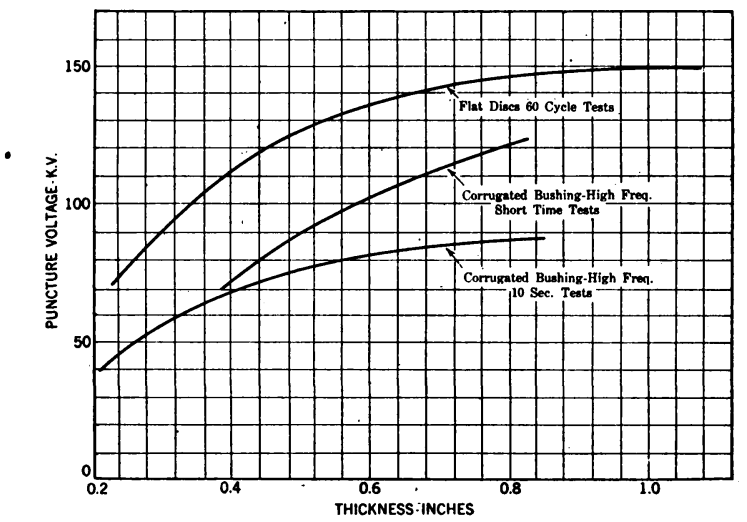

Fig. 29

Puncture voltage of porcelain. Thickness versus puncture voltage. Curves to illustrate the effects of irregular surfaces of the porcelains and shape of electrode as they influence the puncture voltage. The upper curve is a reproduction of 60 -cycle tests on flat disks. The lower curves are the same as given in the previous figure.

\section{Comments on the Choice of the Form of the Test Pieces of Porcelain}

It has been the custom of previous investigators on porcelain to have made up in the porcelain factory plain disks of varying thickness on which the puncture potential tests were made. These plain disks of porcelain involve the easiest conditions of manufacture, both the drying and the firing being possible with a minimum resultant strain from shrinkage in the body of the porcelain. Consequently the puncture potential shown by these investigators is necessarily very much higher than shown in either curves 2 or 3 of Fig. 28. Such a curve taken at 60 cycles impressed is shown in Fig. 29, taken from results published by W. 
F. Fellenberg, together with our average curve of Fig. 28. Any careful designer would take a factor of safety on the values obtained from the tests of such disks which would bring the working values even less than curve 3 . The form of the porcelain part is a very important factor in the resultant dielectric strength and therefore it seems permissible to make tests on the actual porcelain parts irregular as they may be. In order to decrease the cost of such tests, comparatively small electrodes were used, a copper strip $0.12 \mathrm{in}$. thick and $2 \mathrm{in}$. wide rounded at the surfaces that come in contact with the porcelain, and these electrodes were moved from point to point on the porcelain part tested. By getting a great number of tests a much better average value could be obtained than from a dependence on a single test. Knowing that the small electrodes would cause a high potential gradient at the surface of the porcelain this practise may well be brought into question. I believe it is justified, however, by the fact that in testing either a bushing or an insulator in air corona sparks creep out over the surface and the dimensions of such a spark are comparable to that of the electrodes we employed. Therefore, the potential gradient at the surface of such a spark might be at least as great as that produced by the strip electrode that we used. The corona is evenly spread over the surface of an insulator near the caps and pins and therefore there would not be the sharp outline of a spark. There is, however, at the end of the pin and at the edge of the cap of a suspension type insulator the same concentration of potential gradients. On the whole we conclude that the use of the narrow electrode for testing under oil up to $90 \mathrm{kv}$. is justifiable in the condition in which it is used and gives reliable results. For higher voltages the time of application of voltage musi be made very short to limit local damage by potential gradient. Some illustrative tests of this point are given later.

\section{The Relation of Puncture Voltage to Thickness of Porcelain for Different Mixes and Firings}

There are three curves given in Fig. 30 showing the puncture potential of three different mixes of porcelain. The upper curve and the lower curve of the three are the puncture potentials taken on suspension type insulators and the middle curve on corrugated bushings. Therefore there exists a difference in form as well as a difference in material. The results show that there is no very wide variation between the different mixes of 
clay although the color varied from a pure or bluish white to a light yellow. The porcelain which gives the lowest puncture voltage in the curves of Fig. 30 had previously given in other samples tested through the head even better dielectric strength than the samples which gave the data for the upper curve. The weakness may be attributed to the shrinkage strains coming from the presence of the petticoats on the skirt where the voltage was applied. So far as the study has been carried it would seem that the different manufacturers of porcelain have their ups-and-downs of luck and while one mix will be found high in dielectric strength at one time due to having the several factors of porcelain manufacture combined under favorable conditions, they will have other periods when poor combinations will take place and the porcelain will run a little lower in dielectric strength. It would seem that "eternal vigilance" is the price of obtaining a uniformly

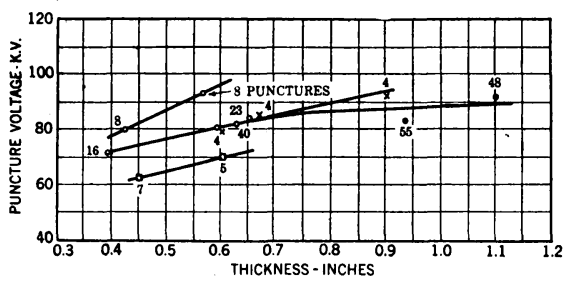

FIG. 30

A comparison of the average puncture potentials of a number of different mixes of porcelain. All tests were made on irregular surfaces. The numbers at the points represent the total number of tests made for each thickness.

good product. In making designs of porcelain it is essential to use the puncture potential corresponding to the minimum average that a porcelain factory can produce.

58. The Technigue of Development of Faults and Punctures in Porcelain and Methods of Examination

When porcelain punctures, the current may cause a single streak or it may cause a crack and, if so, the discharge usually flattens out in the crack, dividing into several paths. If the puncture occurs under oil the current will usually carry oil with it, which is carbonized in the heat of vapor of the electrodes, and both together produce a black streak which is easily seen after the porcelain is broken into pieces. The marking depends somewhat on the duration the discharge is allowed to play through the puncture. 
After the porcelain is broken up the hammer blows or pressure which is used to break it up will produce cleavage surfaces and cracks which did not exist in the porcelain before it was smashed. It is important to determine what cracks existed before the electrical test was made, what cracks were produced by the electrical test, and their extent, and what closed laminations existed in the porcelain. These three faults should be differentiated from the cracks resulting from the mechanical destruction of the porcelain piece. Otherwise stated: after a piece of porcelain is smashed to pieces it is in general impossible without a preliminary stain to detect the cause of the different cracks which appear.

The following technique has been used to advantage in the examination of the porcelains and in most cases has indicated the nature of the fault. In many cases the cause of the fault has been traced to a particular condition of manufacture which needs to be improved. In beginning the tests of a piece of porcelain, then the first step is to determine the presence of accidental flaws so far as possible. Soaking in eosin stain or aniline violet dissolved in alcohol, under vacuum, allows the penetration of the stain into the open air-pockets and laminations. A dark stain may be used for this purpose. The stain is then washed off the surface of the insulator. Frequently the cracks will be shown up by the streaks where the stain has soaked into them and will not wash off. The insulator is then dried and punctured under oil. It is removed from the oil and the oil is washed out with gasoline or some other solvent of oil. The insulator is then thoroughly dried at a temperature above $100 \mathrm{deg}$. It is then immersed in red aniline stain (alcohol solution) and placed under a vacuum. The red stain will penetrate most of the holes and cracks that are opened up by the punctures. In removing the insulator from the stain it is wiped off, and washed off and dried, to prevent discoloration later in handling the broken pieces. The porcelain is then broken up. The original cracks are shown by the dark stain with a layer of red stain on top and the developed cracks are shown by the red stain alone. In some cases it is found difficult or impossible to remove the oil from a crack and this oil will be found on the surface of the crack as an indicator that the crack was produced by the discharge. Any surface of a broken piece which shows neither stain nor oil, it is natural to infer, is produced by the mechanical strains of the hammer or vise. The alcohol solutions are far more penetrating than solutions in water, such as ink. 


\section{Closed Pores and Bubbles, Known as “ Blebs"}

In the glazes on electrical porcelain, so far examined under a microscope, all have contained bubbles which have the same appearance as the familiar bubbles in common glass. A magnifying glass is sufficient to bring these to view but a magnifying powier of 50 is desirable for careful examination. A magnifying power of 250 diameters usually obscures them because the focus is of such short range that only a part of a bubble can be seen with one setting of the lenses. They are more easily seen and studied in colored glazes than in the clear glaze. The size of the bubble and the number of them differ in the glazes from different manufacturers, - in fact they differ in number on the same piece of porcelain. On ridges the glaze is liable to run thin; in the valleys of corrugations it is much thicker and as many as three bubbles can be found at the same position of the microscope at different depths in the glass. These bubbles are apparently formed by a boiling of the glaze at the temperature of $1310 \mathrm{deg}$. cent.

No significance has been attributed to them so far, but our very recent experiments on the beginning of failure, as given later under tests with potential gradient, indicate that under certain conditions these bubbles may play a not unimportant part in the failure of the porcelain back of them.

The bubbles being formed at high temperature, the gas they contain must be at a partial vacuum and therefore easy to ionize by the application of voltage.

When these blebs appear in the body of the porcelain it is natural to infer that either too much feldspar or other flux has been used, or the temperature of the kiln was carried too high for the ingredients of the porcelain. It is rare indeed that visible "blebs" are found in electrical porcelain outside the factory. Perhaps this is because such pieces will be so soft at the high temperature that they will warp out of shape, and consquently they will be scrapped during the first visual inspection as they are taken from the kiln.

An unusual form of bleb has been found in one kind of porcelain for which no definite explanation has yet been found. The bubbles are of varying size, all visible with the naked eyes, and some of them are as large as one millimeter in diameter. These pockets or bubbles at the surface of a broken piece of porcelain were filled with eosin stain dissolved in alcohol and after thoroughly drying the stain the edge surface of the porcelain was ground off, thus decreasing the depth of bubble. It 
was found that the stain has soaked into the walls of the bubble to a depth greater than the diameter of the bubble. Here is an odd bleb surrounded by open pores. The porcelain was made in an experimental way and the bleb might have been due to a free flux as distinguished from a flux like feldspar in which the potash is bound up chemically until a high temperature is reached in the kiln.

Ceramists state that even the best porcelain contains minute cavities or pores of microscopic dimensions. This structure may be called the natural one for porcelain and the term "bleb" does not apply to it. It is probable that the granular or flaky structure of the porcelain is the characteristic that makes it less brittle than glass.

\section{The Hot and Cold Test}

Strains and laminations will usually be developed by a hot and cold test on the porcelain. This test has been used by a number of investigators and consists of transferring the porcelain periodically from boiling water to cold water. After a few transferences of this kind the insulator can then be soaked in stain under a vacuum to mark the cracked surfaces. A partial crack developed in this way will be completely developed by a high-potential high-frequency test. A complete crack from suface to surface of the porcelain will be indicated by a megger test. By using the megger test first it is possible to distinguish between partial cracks and complete cracks.

Regarding the question of the fairness of the hot and cold tests, we must again look to the conditions which occur in practise. It sometimes happens in certain climates that a hail storm will occur on a very hot day. The insulator and pin are at or above atmospheric temperature and a shower of hail or equivalent ice-cold water falls on the top of the insulator. This cools the upper exposed surface, leaving the lower ones warm. In the winter-time it occasionally happens that the temperature will change from a low value into a warm rain. This gives the insulator the other extreme of change of temperature.

It would seem from these two conditions that a hot and cold test carried over a range somewhat greater than that which may occur in practise is a justifiable test. It should be noted that the hot and cold test may develop mechanical strains in the porcelain which are present but normally are not faults. It is conceivable that a hot and cold test may produce strains and 
faults which did not exist before the temperature changes took place, due to a lack of elasticity in the porcelain and cement. Unless there is air in the porcelain it has not yet been determined whether such latent faults would always be developed with certainty by the electrical test, although the-tests given would indicate that they would be. Theoretically the electrical test should strain the porcelain mechanically and might develop the faults. It should be recalled that we have shown by Fig. 23 that the electrical test when carried to the limit develops a puncture along those lines where shrinkage strains were greatest. Everything else being equal, we may tentatively infer from these tests that the shrinkage strains decreased the dielectric strength about 30 per cent.

\section{Hot and Cold Tests Applied to Suspension Type Disks}

Insulators from three different manufacturers, foreign and domestic, were used. The insulators were carefully tested to arc-over value and showed no puncture. The first set of hot and cold tests consisted in placing the insulators first in water at $66 \mathrm{deg}$. cent. and then in water at $9 \mathrm{deg}$. cent. for periods of 10 minutes each. Four insulators total were tested and none of them was cracked by this test.

In the next test the insulators were plunged into hot water at $100 \mathrm{deg}$. cent. for five minutes, then taken out and allowed to cool. In a subsequent test the voltage was not carried up to arc-over value but sufficiently high to give heavy corona discharge with potential from the oscillator. One of the four insulators punctured. We will designate these four insulators by $\mathrm{A}, \mathrm{B}, \mathrm{C}$, and $\mathrm{D}$.

Insulator $\mathrm{D}$, the punctured one, was replaced by insulator D-1. The four insulators were again immersed in boiling water for 10 minutes, then plunged into cold water at 9 deg. cent. for 10 minutes. Insulator D-1 punctured under subsequent tests. Three more insulators were now added, which will be designated by B-1, C-1, and D-2. These insulators were then alternately immersed three times in boiling and three times in cold water at $9 \mathrm{deg}$. cent., each for 10 minutes. It was found that D-2 was punctured but all the others were normal. Insulators D-3 and D-4 were now added and all of them were again placed in boiling water for three minutes and in cold water immediately afterwards, and then tested. In this case no punctures were produced. 
It should be noted that the insulators designated by $\mathrm{C}$ and $\mathrm{D}$ were made by one manufacturer and the difference in their ability to withstand the temperature changes was due to the form and vitrification of the porcelain and certainly not to the ingredients.

\section{Additional Tests to Determine the Quality of Porcelain}

Space does not permit of a description of other tests which have been made to determine the quality of porcelain, since it is desired here to show particularly the application of the oscillator and the new results which may be obtained with it. These other tests, however, are of varying importance and may possibly be given later. For example, the mechanical impact test with a varying weight is important in determining the fragility of the porcelain. Of the other tests along this line are the ring of porcelain when struck, tensile strength, compressive strength, abrasive resistance, tests for toughness or brittleness, $x$-ray tests, microscopic investigation with etching, dielectric constant as a basis of comparison, absorption tests, and so forth.

63. Tests with Continuous High Frequency from an Alexanderson Alternator

It seems desirable to distinguish at this time between the results obtained by high-frequency wave trains such as are generated by the oscillator and continuous high frequency as generated by an alternator giving 100,000 to 200,000 cycles continuously. In practise there is no known strain on insulators corresponding to a continuous high frequency. Therefore there is no reason for using the high-frequency alternator in a standard test, much less so in fact than using 60 cycles as a standard test for insulators. However, the high-frequency alternator can be used in special tests to determine dielectric losses.

\section{Testing with Wireless Outfits}

The usual apparatus used in sending wireless messages produces a series of wave trains of somewhat the same form as the oscillator already described. It is usual, however, to use a frequency of several hundred cycles per second in place of the 60 cycles per second. This gives a little more heating than an equal voltage furnished from the oscillator. There is a considerable difference in the practical handling of the two methods. 


\section{Comparison of Smooth and Corrugated Surfaced Bushings}

It is well known among designers that corrugation and petticoats on the surface of bushings increase the spark voltage. The following study was made to determine the laws of variation of spark voltage with increase of length of bushing, both smooth and corrugated.

Four test samples were used. No. 1 corresponding to curve 1, Fig. 31, was a porcelain bushing one inch thick, having a depth of corrugation of $\frac{1}{4}$ in. The thickness of porcelain in all of this data is always measured at the minimum point, that is to say, at the deepest part of the corrugation.

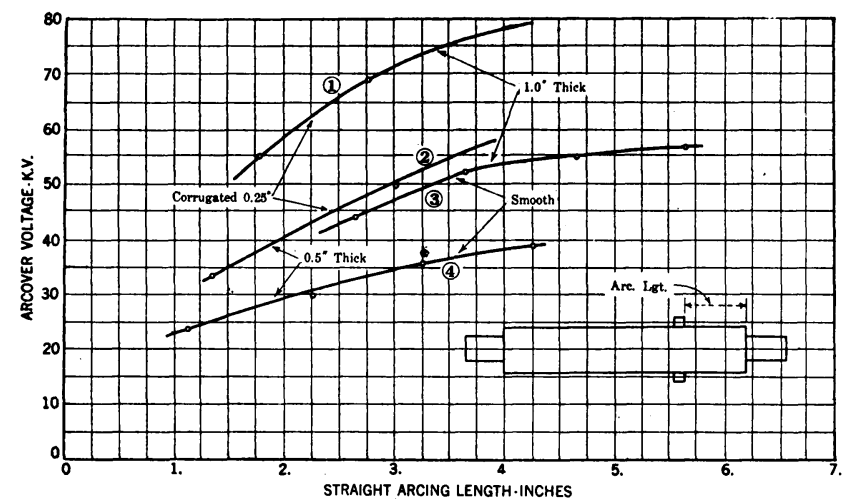

FIG. 31

The relation of length and thickness to the arc-over voltage in air of porcelain bushings and also a comparison of smooth and corrugated surfaces. Tests made with the oscillator. The relation is given between straight arcing length in inches versus the kilovolts arc-over voltage.

Test piece No. 2, corresponding to curve No. 2, was $\frac{1}{2}$ in. thick with $\frac{1}{4}$ in. corrugations.

Test piece No. 3, corresponding to curve 3, had a thickness of one inch and a smooth surface.

Test piece No. 4 , corresponding to curve 4 , had a thickness of $1 / 2$ in., and a smooth surface. These curves show the relation between the arc-over voltage and the arc length measured straight from electrode to the end of the test piece, but not taking into account the increased length due to corrugation and thickness at the end. The tests were made by placing a metal rod inside the porcelain bushing and placing a metal ring around the porcelain at different distances from the end to give different spark lengths in air along the surface of the porcelain. 
To compare the corrugated to the smooth porcelain, curves 1 and 3 may be used, both having one in. thickness of porcelain, or curve 2 may be compared to curve 4 , both pieces having $1 / 2$ in. thickness. The effect of thickness can be obtained by comparing curve 1 and curve 2 , both of which are corrugated but of different thickness; or by comparing curve 3 and 4 , both of which are smooth but of different thickness. As an example it is seen that for an arcing length of $31 / 2$ in. and a thickness of one in., the arc-over voltage for a smooth surface bushing is $52 \mathrm{kv}$. Corrugating this surface with ridges $1 / 4$ in. high raises the spark potential to $77 \mathrm{kv}$. From these data the relative effect of the corrugations can be seen. This relative value of corrugating is brought out by making comparisons of the spark-over voltages for different arc lengths at any desired point.

\section{Study of Arc-Over Voltage of Bushing, Using Super- Spark Potential from the Oscillator}

All the studies so far carried out have been on the basis of producing a design of porcelain of sufficient dielectric strength to withstand the voltages necessary to cause an arc-over when the applied voltage is gradually raised. This is the condition in the standard practise of testing as carried out today.

We are now to look forward to a more ideal design of insulators in which the requirements are going to be very much more severe. In practise, insulators are subjected to momentary lightning surges in which the potential may be very much above the value necessary to produce a spark. This high potential is very quickly relieved by the movement of the lightning surge along the circuit. If the relief is sufficiently rapid the super-spark potential may be applied to the insulator without causing an arc-over simply because the arc has not had time to form. In line insulators it is absolutely essential that this super-spark potential shall not cause a puncture from electrode to electrode through the porcelain. The brief time required to puncture the porcelain must be greater than the time necessary to form the creepage spark around the skirts of the insulator through the air; otherwise a puncture will be produced.

In the case of porcelain bushings, the problem is somewhat different from the design of a line insulator. This difference comes from the fact that the porcelain bushing is used on a definite piece of electrical apparatus such as a transformer, motor, potential regulator, meter, etc. and there is need of a lightning 
arrester at this point. If it is possible and reasonable to do so, a porcelain bushing should also be designed with the criterion that it should always arc over before it punctures. We shall see later that this may lead to great difficulties and it may be deemed advisable by the designer to use a different basis. Since the bushing is protected by a lightning arrester in the neighborhood it should be possible to find a factor of safety against puncture of the porcelain which is sufficiently high to be above the maximum potential that can exist across the bushing as limited by the lightning arrester. At the present time this factor of safety is unknown due principally to the lack of information regarding the voltages which may come from local oscillations, such as would create momentarily a higher voltage at the bushing than exist at the terminal of ihe lightning arrester. It is impossible to place all the lightning arresters quite near all the bushings which they are to protect. However, it is a tenable hypothesis that a factor of safety can be chosen which will put the spark potential of the porcelain bushing above the maximum potential that can exist across the lightning arrester for any intensity of discharge, with the exception of a direct stroke. If this standard of design is adopted a bushing may be used which cannot be tested to the voltage which would cause an arc-over. In other words, in a long bushing with much exposed surface to mitigate bad effects of dust collection, the requirements of test shall be changed to suit these new conditions. The test should then carry the test voltage up to a value corresponding to the factor of safety chosen, say three or four. Nevertheless, the same standard made for the insulator is desirable for the bushing if it can be attained practically. To summarize then, line insulators which have no lightning arrester protection must of necessity be designed so as to withstand a super-spark potential without puncturing, being always protected by an arc over the surface of the porcelain.

The plan is now to make an experimental investigation of what conditions must exist in porcelain bushings in order that the super-spark potential shall cause an arc-over rather than a puncture.

The first test is made on a smooth surface bushing $\frac{3}{8}$ in. thick and a length along the surface of $\mathbf{1 . 9}$ in. The generated potential of the oscillator was gradually raised in successive steps from the arc-over voltage $(27 \mathrm{kv}$.) to its maximum value of $170 \mathrm{kv}$. corresponding to $10 \mathrm{kv}$. on the control gap shown as abscissas in Fig. 32. As the momentary impressed potential 
is increased from $27 \mathrm{kv}$. to double that amount the gap in parallel with the bushing shows an increase in potential from $27 \mathrm{kv}$. to $32 \mathrm{kv}$. This increase of 19 per cent in the equivalent spark voltage at the terminal of the bushing for 100 per cent increase in the applied super-spark-voltage represents a logarithmic time curve of discharge, the time decreasing rapidly with the increase in voltage. When the super-spark potential has been increased 24 times the arc-over potential, the equivalent gap in parallel with the bushing shows a maximum rise of voltage to $50 \mathrm{kv}$. which is slightly less than twice the arc-over voltage.

From the point of 24 times the arc-over voltage, to the super-

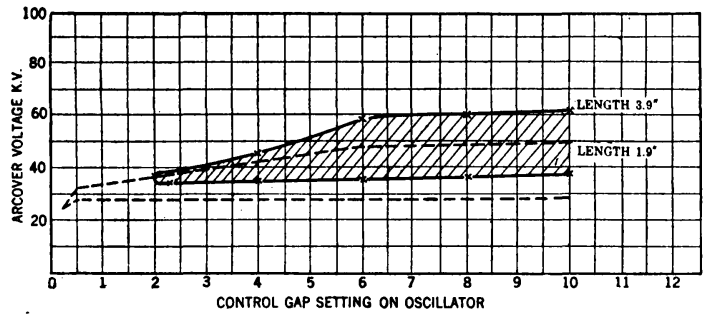

FIG. 32

The relation of arc-over voltage on a smooth porcelain bushing $0.38 \mathrm{in}$. thick when voltages above the spark voltage, that is, super-spark voltage, is applied. Tests made with the oscillator. Relation is shown of control gap setting versus arc-over voltage as measured by a gap in parallel with porcelain bushing. Control gap setting corresponding to the maximum voltage generated in the coreless transformer. This maximum voltage generated is considerably above the values measured by the gap when the voltage is above minimum value that will cause an arc-over. Two different sets of curves are shown. Each curve has two branches. The upper branch represents the maximuin gap which causes all the discharge to take place across the bushing in parallel. The lower branch shows the maximum gap setting which will just take away all discharges from the bushing in parallel.

spark potential of 40 times the arc-over voltage, the equivalent gap in parallel with the bushing increases only $2 \mathrm{kv}$. more. In other words, the maximum possible potential that may be impressed on this bushing is of the order of double the arc-over potential. We might look forward at this time to our method of design. If we were choosing the thickness of this bushing for a design that would withstand super-spark potential without puncture we would turn to a puncture curve of porcelain under oil and choose from this curve a thickness and grade of porcelain which would not puncture on $50 \mathrm{kv}$. applied. This bushing would then arc over for super-spark potentials of 175 kv. at 300,000 cycles and should be proof against puncture.

In this same set of tests another factor was studied, namely 
the factor usually determined in the design of lightning arresters. What gap must be placed in parallel with the bushing such that the discharge will always take place over the parallel gap rather than over the bushing? In terms of lightning arrester design, what equivalent gap must a lightning arrester have so that it will always take the discharge of high potentials away from a bushing and thereby give it protection from arc-over? In Fig. 32 the lower branch of the curve shows a practically constant voltage setting of $28 \mathrm{kv}$. on the gap to take the discharge even when the super-spark potential was as great as $175 \mathrm{kv}$.

In the next step the length of the same smooth surface bushing was increased from 1.9 in. to 3.9 in. The same system of tests was applied and is shown (Fig. 32) in the corresponding pair of curves with cross hatching between them. There is one feature of special note shown by this curve which is different from the previous one. The lower part of the curve, that is the parallel gap which will protect the bushing from arcing over, is considerably less than the arc-over voltage of the bushing. For example, the arc-over voltage is $38 \mathrm{kv}$. With a superspark potential of twice the arc-over potential the gap must be reduced from $38 \mathrm{kv}$. to $34 \mathrm{kv}$. in order to take the spark away from the bushing. Again this curve shows a change of direction at a point on the control gap marked $6 \mathrm{kv}$., corresponding to about $100 \mathrm{kv}$. momentarily impressed on the gap. We must not conclude that the curves representing the equivalent gap in voltage are actual voltage. It is impossible in the present state of knowledge to accurately state what the impressed voltage is from the setting of the spark gap. The dielectric spark lag enters therein, and is affected by various conditions. We must take into account also that the impressed frequency in this case is about 300,000 cycles and that the equivalent gap would change somewhat by a change in the frequency, this being due to a relation between the wave front and the dielectric spark lag of the gap.

\section{Further Tests with Super-Spark Potential}

In Fig. 33 are shown two sets of curves taken on bushings with corrugated surface. The sparking length of bushing in the lower curve was $1.75 \mathrm{in}$. and in the upper curve $3.9 \mathrm{in}$.

As before, the abscissas are proportional to the applied superspark potential and the ordinates represent the potential as measured by the sphere gap. There are two curves for each 
setting of the super-spark potential, one minimum equivalent gap which takes all the discharge and one maximum equivalent gap in which all the discharge is transferred to the bushing which is connected in parallel with the gap.

These curves show the same general outlines as the previous tests on smooth-surface bushings. The corrugated bushings, however, show a very much higher test of voltage which is due to the greater difficulty in forming a creepage spark over the hills and valleys of the corrugations. The spark will run over the outside surface, parallel to the conductor in the center of the bushing, fairly easily, but when it has to climb one of the ridges of the corrugation at a considerable angle to the central conductor it requires a very much higher voltage to produce the creepage spark. Once over the ridge the spark can again

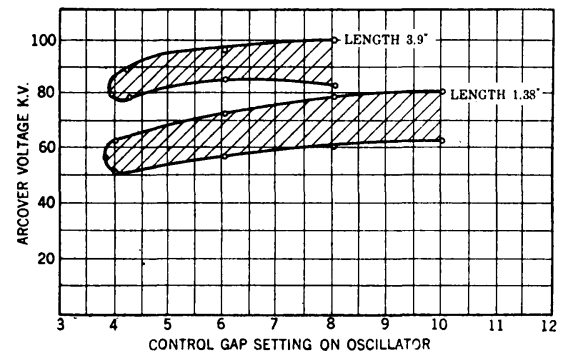

FIG. 33

These relations are entirely similar in every respect to the curves given in Fig. 32 except that the thickness of the bushing was one in. and the surface was corrugated with ridges 0.25 in. high. (In the lower branch of the upper curve, at $6 \mathrm{kv}$. setting on the control gap, is an error. It should be $82 \mathrm{kv}$.)

dart down into the valley. of the corrugation with ease but is again retarded as it climbs the next ridge of the'corrugation. This condition has been illustrated elsewhere and it does not seem necessary to reproduce the illustrations at the present time.

Formulas For the Laws of Variation of Super-Spark Potential vérsus Arcing Length on Corrugated Bushings

Many tests were made on different forms of insulators and it was found that the law of creepage spark was usually of the nature of an exponential curve within the range of lengths and thicknesses studied. The different formulas need checking in extrapolated points and for this reason they are not published at the present time. The points given for the curves of superspark potential fall approximately on a straight line when plotted 
on logarithmic paper. The curves are represented by the following formula:

$\mathrm{V}=50 t^{0.682} L^{1 \cdot 05}$ (porcelain corrugated)

$\mathrm{V}=$ Maximum measured super-spark voltage in $\mathrm{kv}$.

$t=$ Minimum thickness in inches

$L=$ Distance from outer terminal to end of bushing in inches.

68. Testing of Strings of Insulators with the 300-Kv. OsCillator

When the problem of testing disk insulators in strings is undertaken the oscillator shows some marked advantages over the 60 -cycle method. The oscillator has dimensions and cost which are only a small fraction of a 60-cycle outfit. In designing 60 -cycle transformers there is nothing gained by using extremely small wire and therefore the dimensions of the transfomer for a voltage of $500 \mathrm{kv}$. to $750 \mathrm{kv}$. are necessarily comparatively large.

The several insulator disks in series in the suspension type insulator have separated electrodes which give what may be called the multi-gap effect, each iron electrode on the insulators having a capacitance to ground as well as to the adjacent one. This theory was first explained by Dr. Steinmetz in 1906 in relation to the multi-gap arrester. He showed that the concentration of voltage at the end gaps of the lightning arresters was due to the capacitance of each metal cylinder to ground. It is now common knowledge that the same condition exists in a string of suspension insulators and the voltage is unevenly distributed throughout the string, as has been shown by several investigators. The disk next to the line takes the largest percentage of voltage.

After noting this theory, it is somewhat confusing to find that in testing a string of insulators it is not the end disks which are most liable to puncture. Some tests were made which show that the insulator farthest from the end is the one most frequently punctured by the high frequency wave trains from the oscillator. Five insulators were placed in series and connected to the oscillators having no ground at either end. This places the third insulator at zero or earth potential. Out of 21 insulators punctured 13 of these were in the location of the third disk, four were in the location of the second disk, and two in the corresponding symmetrical location of the fourth disk. There was only one insulator at each end of the string that was punctured in all the tests Making comparisons between these different conditions, the middle disk of a string of five punctured 13 times as many 
times as the end insulators. It also punctured 3 to 6 times as many times as the adjacent disks on each side of it.

The explanation of this phenomenon seems to be that of difference in super-spark potential on the disks in the different locations. As a tentative explanation the following is given: When the high voltage high frequency is applied to this string of insulators the distribution of potential gives the greatest potential at the end disk and the least at the middle disk. However, the total voltage applied to the end disks is not extremely high because of the partial distribution along the string. The applied voltage is somewhat higher than the value necessary to cause a spark. The end disk sparks over and there is thrown sudderilyon the three remaining disks a super-spark potential of considerable value due to the short-circuiting of the end disk by the spark. The duration of time considered is of the order probably of a few millionths of a second. The total voltage applied in these tests, approximately $350 \mathrm{kv}$., is now divided somewhat unequally between the three disks. If the second and fourth disks are not punctured by this excess voltage they will spark over and the middle disk for a moment will receive a voltage of nearly the full value of $350 \mathrm{kv}$. As a result the middle disk is very liable to be injured.

The effect obtained by the concentration of voltage on the end disks and their successive elimination by sparking around the skirts of the disks is very much like using one insulator on this oscillator and suddenly discharging against it an impulse of 350 $\mathrm{kv}$. The actual spark potential of the disk is about $85 \mathrm{kv}$. which leaves a super-spark potential of $265 \mathrm{kv}$. This effect is exactly like the one obtained from a lightning stroke on the line. I think it very probable that operators of transmission lines can confirm the statement that lightning does damage disks from time to time that are nearer the ground terminal than the line terminal of the string of disks.

It is important to add further information in regard to the duration of the tests. In each case the 60 -cycle potential was applied to the oscillator for a period of five seconds. The test was then discontinued for five seconds, giving the insulators a rest, and then re-applied. In order to puncture the middle insulator the number of applications of five seconds duration are given as follows: $8,7,21,9,1,18,4,50,18,16,10,8,1$.

The number of applications of five seconds each to puncture the six adjacent disks, namely the second and fourth in the string were as follows: $30,1,39,16,8,3$. For the end disks, 
namely the first and the fifth, there were 9 and 11 applications of five seconds duration. Each second represents 120 wave trains applied to the insulator so that each application, as given in the above list, means 600 wave trains discharged against the string.

In the data given above there is no statement made of the number of times that the impulses were applied without causing damage. The method of test was to continue to apply the voltage to the string of insulators for five-second periods until at least 50 applications could be made without damage to the string of insulators. Then a new string was installed and as fast as the disks were punctured they were replaced until the string showed its ability to withstand the tests. In the first string there were 50 applications of five seconds duration finally applied without causing damage. In the second string 120 applications were finally made without causing punctures. In the third string there were also 120 applications without causing puncture. In the fourth string of insulators there were 50 applications without causing puncture. These tests tend to show that the insulators are designed so that they can withstand this test. It is an extremely severe test and under present conditions of knowledge and manufacture it would seem to be unfair by being unduly severe. The tests are given not as recommendations but as information on the subject.

In regard to the location of the punctures; 50 per cent took place in the head of the disk and 50 per cent at an average distance of one in. out on the porcelain skirt. Another series of tests was made in which the duration was only $\frac{1}{2}$ second with two-second intervals of rest. It was found that a shorter duration was of very much less severity to the porcelain than the longer duration. Damage is therefore being done to the porcelain in a manner which will be illustrated later under potential gradient tests. While the arc-over potential of these disks was in the neighborhood of $85 \mathrm{kv}$. the puncture potential under oil was $128 \mathrm{kv}$. and $150 \mathrm{kv}$. which gives a factor of 150 per cent and 176 per cent. The study of the necessary dielectric strength to puncture, similar to the one already given for bushings could be made with an oscillator and thereby determine what factor is necessary in order that the suspension disks shall always spark around the skirts rather than puncture. No previous tests were made under oil on any of the disks that punctured to determine if their factor of safety was as high as the two given 
above. It is desired at the moment simply to point out that it is a comparatively easy investigation to make with the oscillator although precaution must be taken to limit the duration of the test to the value that will not cause local damage to the porcelain by corona in accordance with the values determined from the potential gradient tests, examples of which are given later.

\section{Potential Gradient Tests with the Oscillator not Carried to Puncture of the Porcelain Piece}

Test piece was a porcelain bushing, $1314 / 16$ in. long with a minimum diameter of $310 / 16$ in. outside and $16 / 16$ in. inside approximately. The thickness of the porcelain was 0.94 in. From bottom to top, as it stood in drying and in firing, there are eleven grooves on the lower half and nine grooves on the upper half. The tests were started on the top groove, No. 20. Inside the porcelain tube an iron pipe was placed and on the outside was placed our standard electrode which is 0.12 in. thick and 2 in. wide rounded at the edges. The porcelain was immersed under transil oil to a depth of 2 in. The duration of application of voltage in every test was five seconds. On the 20 th or top groove the first potential applied was $60 \mathrm{kv}$. and in each succeeding groove, there were $10 \mathrm{kv}$. added. When 120 $\mathrm{kv}$. was reached and applied for five seconds the porcelain punctured. The detailed results of these tests follows.

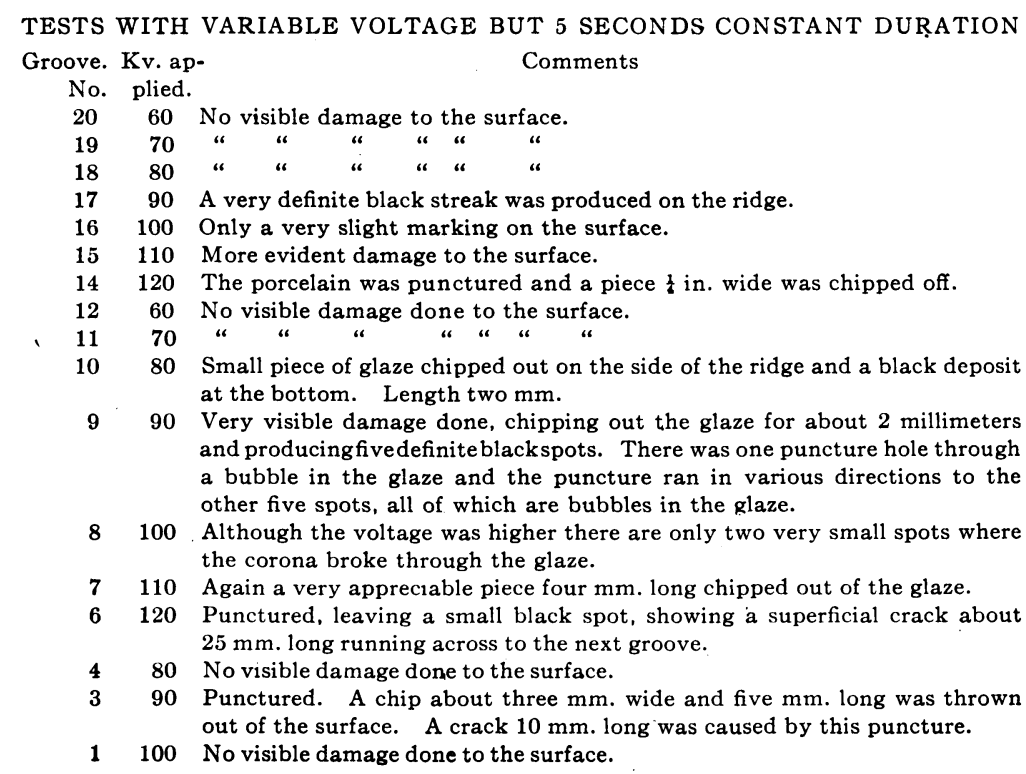


Further Comments. A microscopic examination was made from 25 diameters to 250 diameters. The damage to the surfaces is done by the combination of potential gradient and heat of the corona. It seems evident from these tests that there is a considerable difference in the dielectric strength of the porcelain in different spots as evidenced by the fact that some, say at $100 \mathrm{kv}$., did not scar the surface where tests at $90 \mathrm{kv}$. did. This naturally leads us to the possibility of examining the homogeneity of porcelain by means of potential gradient as distinguished from the ordinary potential tests. Such a study will be described later.

\section{Potential Gradient Tests on Porcelain with the Electrodes so Arranged that Puncture could not take Place}

In the previous test given, the lines of electrostatic force were perpendicular to the surface of the porcelain due to the fact that a long metal electrode was used inside the porcelain bushing and the other electrode was placed against the surface in a valley of a corrugation.

In the test now to be described the internal electrode was removed from the bushing and placed in the oil at a horizotal distance of 9 in. from the center of the porcelain bushing and at about the same distance from the other electrode which rested on the upper surface of the bushing. The lines of electrostatic stress were carried through the porcelain to a certain greater extent than through the oil due to the fact that the dielectric constant of porcelain is about $2 \frac{1}{2}$ times that of oil. However, there was no tendency to puncture the main body of the porcelain and the only effect obtained was the intense voltage gradient at the surface of the porcelain on which the small electrode rested.

In the first group of tests the time of application was $10 \mathrm{sec}-$ onds and the potentials used varied in the seven different grooves tested from $120 \mathrm{kv}$. down to $70 \mathrm{kv}$. The general results of these tests were negative, that is to say, no markings were caused by the potentials applied.

In the second group of tests the porcelain bushing was rotated about $80 \mathrm{deg}$. from its previous position. The time of application of potential in each of the ten tests made was five seconds. The results show the gradual development of faults. 


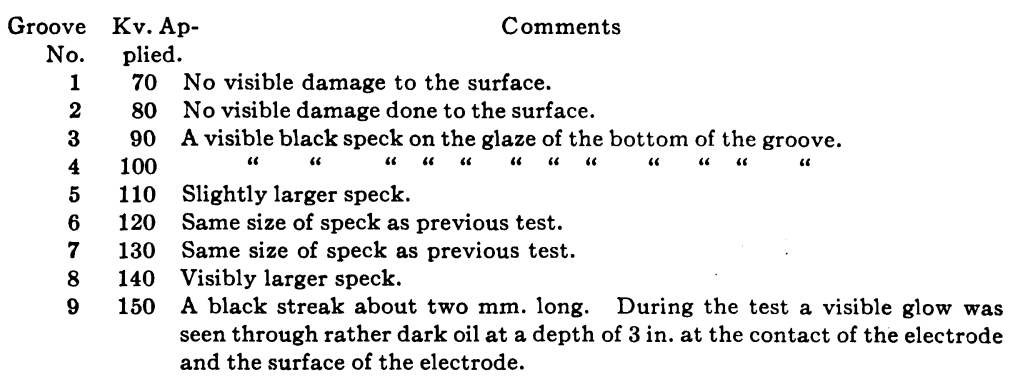

Comparing the second group of tests to the first group, it should be noted that in spite of a reduction of time from ten seconds to five seconds, damage was done at the same voltage which indicates perhaps weaker porcelain.

In the next test which was made on groove 10 , the time of application of potential was increased from five seconds to 30 seconds and the voltage was maintained at $150 \mathrm{kv}$. As a result a black streak about three $\mathrm{mm}$. long was produced on the surface of the porcelain. A microscopic examination showed two puncture holes in the glaze and a black streak running along the surface of the porcelain. The diameter of the punctured holes in the glaze was about equal to the size of the bubbles in the glaze.

In the third group of tests the time was made uniformly 30 seconds for each step. The same angular position was used as in the previous tests but the distance was $3 \frac{1}{2}$ in. farther up on the bushing.

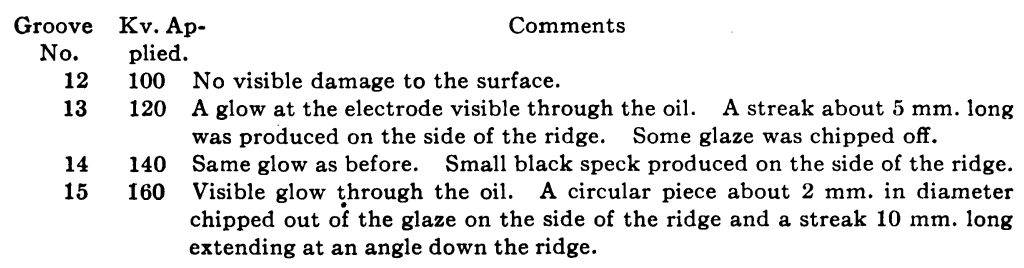

Conclusions. So far as the data go we must conclude that the quality of the porcelain varies at different points of the surface. The damage is apparently done by an extra large displacement current at the surface which causes local heating by the spark. These tests apparently indicate a new method of investigation of homogeneity of porcelain. They have not been carried far enough to determine all the causes of differences found. 


\section{An Examination of the Surface of a Porcelain Bush- ing by Voltage Gradient Tests}

After considerable preliminary work the following basis of test was determined upon. A corrugated porcelain bushing of uniform thickness was immersed in oil with a rod $3 / 16$ in. diameter through the center of it. Around the bushing in the valley of a corrugation was placed a copper wire 0.05 in. diameter. Between these two electrodes there was applied $120 \mathrm{kv}$ ، during a period of five seconds, using the oscillator as a source of power. As a result, the voltage gradient at the surface of the wire caused more or less small black spots or scores. The electrode was then moved into the valley of the adjacent corrugation and the test was repeated until all the 20 corrugations were covered. An examination was then made of the surface of the porcelain and it was found that in certain localities there were no spots and in certain other localities there were a considerable number of spots. The development of the surface of the porcelain is shown in Fig. 34 with the location and the relative sizes of the spots.

Since at the start the potential gradient at all parts of the encircling wire was quite uniform these tests show a difference in the dielectric current in the porcelain. The exact nature of this difference is not determined at the time of writing but it is evident that it represents a difference in homogeneity of the porcelain. It cannot be stated that this difference represents a serious or important difference in this particular piece of porcelain. At the same time it would seem that this electrical method would be a convenient one for examining variations in the porcelain as they might be affected by non-homogeneous distribution of ingredients, of drying, or perhaps some other factor.

Knowing that the bubbles in the glaze are the beginning points of the damage to the surface and still further knowing that the expansion of a spark into a bubble would give a greater concentration of voltage gradient at this point, it was thought possible that the beginning of the trouble was due entirely to the accidental location of bubbles in the glaze. While this may be true it was necessary to make further tests to determine if there was a real difference in the quality of the porcelain underneath the glaze. The porcelain bushing was taken to a carborundum wheel and the glaze was carefully ground off in the valleys of the corrugations. The previous tests were then repeated and are shown in the three lower lines of Fig. 34. The damage done in the previous tests was entirely superficial and the black spots disappeared during the grinding off of the glaze. The new spots shown for 
corrugations 13,7 and 3 occurred in the same general locality that they did in the previous test when the glaze was present. This tends to prove that the porcelain varies in quality throughout the bushing.

\section{When Does the Test Damage Good Porcelain?}

It was found in the voltage gradient tests that when the voltages over $100 \mathrm{kv}$. were applied the damage to the porcelain started

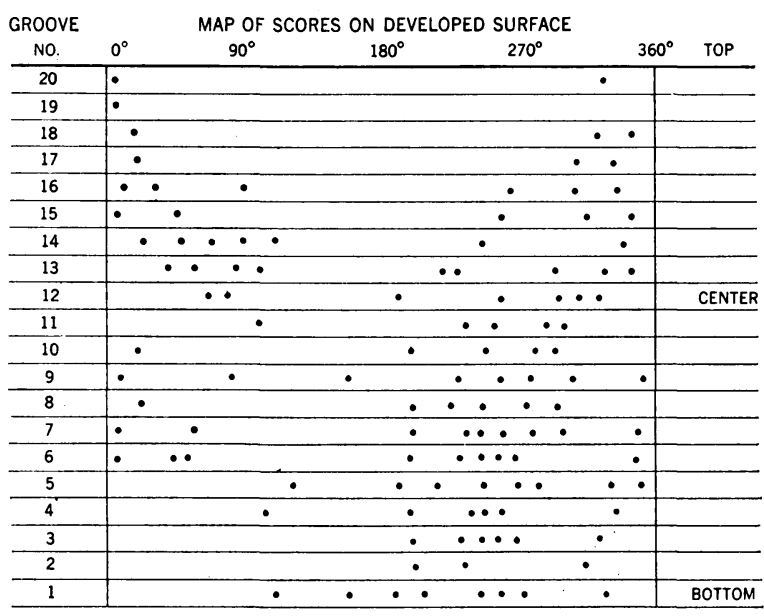

GLAZE GROUND OUT OF 3 CORRUGATIONS AND RE.TESTED

\begin{tabular}{|c|c|c|c|c|c|c|c|}
\hline 13 & ․ & $\bullet$ & - & • & 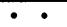 & - $\bullet$ & • \\
\hline 7 & $\bullet$ & & & & $\bullet$ & & \\
\hline 3 & & - & - & & $:$ & • & \\
\hline
\end{tabular}

Fig. 34

Map of scored surface of a porcelain bushing to which was applied a voltage gradient test. $120 \mathrm{kv}$. was applied ten seconds. The small black spots represent the beginning of puncture. The variations in the location of the spots over the surface of the porcelain are presumably due to variation in the quality of the porcelain. The small map below shows three tests on grooves which had the glaze ground off. The electrode was a wire 0.05 in. diameter wrapped around the valley of the corrugation in each of the above tests.

in a definite spot and within a few seconds the damage was gradually increased until puncture finally took place. By making a few preliminary trials it was possible to determine roughly the law which determines the voltage and time of application which would damage the surface. These time-voltage applications were then made over the different parts of a porcelain bushing and as a result a certain number of spots were obtained for each application. The spots varied in diameter and somewhat in number. Therefore a certain arbitrary weight was given to the 
size of the spot and the number of spots was taken as a criterion of damage done. Small spots were given a weight of 0.8 of the average. Large spots were given a weight of 1.2 of the average size of spot. Then the time voltage tests which gave approximately the same number of spots were chosen. The results are plotted in Fig. 35.

It must be confessed that this is a rough method of arriving at the curve and yet it is of fair reliability for this quality of porcelain. It shows that at the higher impressed voltage the time of application must be materially less than when the applied voltages are lower. At something less than $100 \mathrm{kv}$. it shows that the tests on this particular sample can be applied for an indefi-

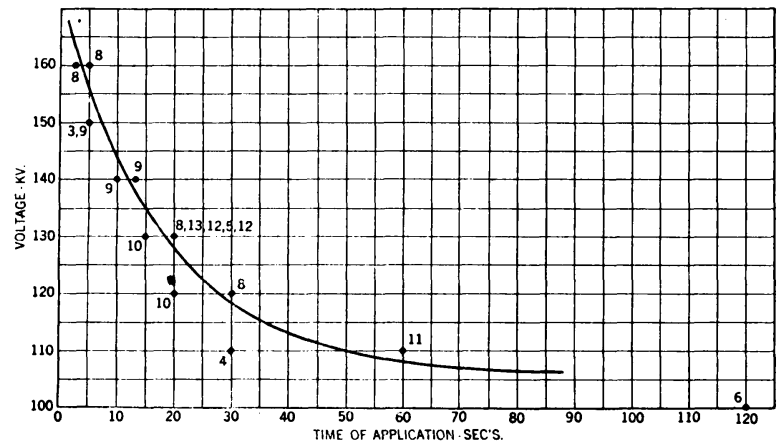

FIG. 35

A rough curve to illustrate the growth of damage to dielectric strength in porcelain bushings at different values of kilovolts applied. At the higher voltages the damage takes place more rapidly than at the lower voltages. This relation gives a rational basis for the proper period of application of test voltage which can be applied without damaging good porcelain.

nitely long time without starting a fault by concentration of voltage at the electrode.

This is the first step in laying out a rational rule for testing of porcelain. Other tests are being made using wires of larger diameter with corresponding variations in the values of potential gradient in order to determine the law of potential gradient versus damage to the porcelain. The potential gradient is extremely high as compared to the value that causes corona in air, (30 kv. per cm.).

In developing the oscillator and gathering the data herein presented the author takes pleasure in acknowledging the assistance of Messrs. P. E. Hosegood, S. Thomson, and G. F. Gray in the development of the oscillator and of Messrs. R. H. Forney and R. H. Marvin in the experimental studies. 